\title{
频 \\ O PROGRAMA FORÇAS NO ESPORTE COMO FATOR DE INCLUSÃO SOCIAL E DESENVOLVIMENTO ESPORTIVO NO BRASIL
}

\section{THE PROGRAM FORCES IN SPORTS AS A FACTOR OF SOCIAL INCLUSION AND SPORTIVE DEVELOPMENT IN BRAZIL}

\section{EL PROGRAMA FUERZAS EN EL DEPORTE COMO FACTOR DE INCLUSIÓN SOCIAL Y DESARROLLO ESPORTIVO EN BRASIL}

\author{
Pedro Georges Galvão ${ }^{1}$ \\ Renata Osborne ${ }^{2}$ \\ Roberto Ferreira dos Santos ${ }^{3}$ \\ Carla Isabel Paula da Rocha de Araujo ${ }^{4}$
}

Resumo. Muitas escolas não possuem espaço adequado para a prática esportiva. Uma alternativa a essa falta de estrutura tem sido a realização de projetos sociais esportivos. O objetivo deste estudo foi verificar se o Programa Forças do Esporte (Profesp), vertente do Programa Segundo Tempo, desenvolvido pelas Forças Armadas, é fator de inclusão social e desenvolvimento esportivo no Brasil. Foi realizada uma pesquisa mista, com aplicação de entrevista e questionários aos coordenadores de polos do programa. Verificamos que o Profesp apresenta algumas barreiras e facilitadores, pode trazer benefícios ou riscos, caso percam o foco principal, e possui pontos fortes e oportunidades de melhoria. Concluímos que o Profesp, por si só, não é fator determinante para a inclusão social e desenvolvimento esportivo do Brasil, pois atualmente não atende a percentual significativo, porém, atende a dezenas de milhares de crianças e adolescentes, o que já o coloca como uma polícia pública relevante para o Brasil.

Palavra-chave: Projetos sociais esportivos. Iniciação esportiva. Inclusão social. Desenvolvimento esportivo.

Abstract: many schools do not have adequate space for sports. An alternative to this lack of structure has

\footnotetext{
${ }^{1}$ Mestre em ciência da atividade física pela Universidade Salgado de Oliveira. Bacharel em educação física pela Escola de Educação Física do Exército. Bacharel em ciências militares pela Academia Militar das Agulhas Negras. Instrutor na Seção de Educação Física da Academia Militar das Agulhas Negras. (pedroggalvao@gmail.com)

${ }^{2}$ Doutora em liderança educacional pela Universidade Florida Atlantic (EUA) e mestre em educação pela Pontifícia Universidade Católica. Professora titular da Universidade Salgado de Oliveira no programa de mestrado em ciências da atividade física, no qual ministra a disciplina métodos qualitativos. (rerafadeo@gmail.com)

${ }^{3}$ Doutor em ciências do desporto e educação física pela Universidade do Porto e mestre em educação pela Universidade Federal Fluminense. Professor titular da Universidade Salgado de Oliveira no programa de mestrado em ciências da atividade física, no qual ministra a disciplina seminário de pesquisa. (rob.fersantos@oi.com.br)

${ }^{4}$ Doutora em ciências do desporto pela Faculdade de Desporto da Universidade do Porto, validado pela Universidade de São Paulo (USP). Pesquisadora científica no Brasil e no exterior em parceria com equipes nacionais e internacionais. Pesquisadora do Centro de Estudos Olímpicos da UERJ. (carla_mpompilho@hotmail.com)
} 
been the implementation of social sports projects. The purpose of this study was to verify if the Program Forces in Sports (PROFESP), part of the Second Time Program developed by the Armed Forces, is a factor of social inclusion and sports development in Brazil. A mixed survey was carried out, with interview application and questionnaires to the program polo coordinators. We find that PROFESP presents some barriers and facilitators, can bring benefits or risks if they lose the main focus, and have strengths and opportunities for improvement. We conclude that PROFESP, by itself, is not a determining factor for social inclusion and sports development in Brazil, since it currently does not meet the significant percentage, but it serves tens of thousands of children and adolescents, which already puts it as a public politics relevant to Brazil.

Keywords: Social sports projects. Sports initiation. Social inclusion. Sports development.

Resumen: muchas escuelas no tienen espacio adecuado para la práctica deportiva. Una alternativa a esta falta de estructura ha sido la realización de proyectos sociales deportivos. El objetivo de este estudio fue verificar si el Programa Fuerzas en el Deporte (PROFESP), vertiente del Programa Segundo Tiempo desarrollado por las Fuerzas Armadas, es factor de inclusión social y desarrollo deportivo en Brasil. Se realizó una investigación mixta, con aplicación de entrevista y cuestionarios a los coordinadores del programa. Verificamos que el PROFESP presenta algunas barreras y facilitadores, puede traer beneficios o riesgos si pierden el foco principal, y tiene puntos fuertes y oportunidades de mejora. Concluimos que el PROFESP, por sí solo, no es un factor determinante para la inclusión social y el desarrollo deportivo de Brasil, pues actualmente no atiende el porcentaje significativo, pero atiende a decenas de miles de niños y adolescentes, lo que ya lo coloca como una la política pública relevante para Brasil.

Palabras clave: Proyectos sociales deportivos. Iniciación deportiva. Inclusión social. Desarrollo deportivo.

\section{Introdução}

A Unesco coloca a prática da educação física e do esporte como direito inalienável do ser humano ("esporte para todos"), o que também é previsto na Constituição Federal do Brasil (BRASIL, 1988) e no Estatuto da Criança e do Adolescente (BRASIL, 1990) e estimula o desenvolvimento de projetos e ações que promovam inclusão social. Na última Conferência Internacional de Ministros e Altos Funcionários Responsáveis pela Educação Física e pelo Esporte (MINEPS), Berlim (2013), que visa a ser uma facilitadora na troca de informações e conhecimentos em educação física e esporte, foram recomendadas políticas concretas que contribuam: a) para o acesso ao esporte como direito fundamental; b) para o estímulo a investimentos em programas de esporte e educação física; e c) para a preservação da integridade do esporte (UNESCO, 2013).

Por inclusão social, Spinieli (2018) entende que é a busca por oportunizar e criar, para todas as pessoas, condições de acesso e participação exequíveis, lembrando que a Constituição Federal de 1988 ordena que não haja discriminação de qualquer forma com nenhum cidadão, 
garantindo assim a busca do direito de igualdade entre todos. Já Significados (2017) traz que a inclusão social é a busca de participação igualitária de todos os indivíduos por meio de um conjunto de ações que visa a esta garantia.

A escola é um ambiente propício às atividades educativas e apresenta intenso convívio social, devendo, por isso, ser encorajada a promoção de hábitos de vida saudáveis no seu ambiente. O estímulo a esses hábitos saudáveis deve ser inserido o quanto antes, aproveitandose inclusive a formação da personalidade que ocorre na adolescência, quando se pode consolidar tais hábitos. Isso pode trazer benefícios para a vida adulta (ENES; SLATER, 2010). Porém, muitas escolas não têm infraestrutura adequada para a prática de atividades físicas e esportivas (espaços, instalações e material), e o desporto escolar torna-se, assim, sem objetividade. Aliado a isso, a baixa remuneração dos professores dificulta seu aprimoramento, até porque, via de regra, eles têm que pagar por conta própria para realizarem cursos de qualificação (MARIA; MARTINS; RENNÓ, 1997).

Cortes Neto, Dantas e Maia (2015) observaram que, além das escolas, o Brasil como um todo vem apresentando cada vez menos áreas disponíveis para atividades culturais, educacionais e sociais devido aos bolsões de moradias que têm aumentado. Com isso, o esporte, que é uma excelente opção para se enfrentar os problemas sociais que afetam o dia a dia das pessoas, principalmente de crianças e adolescentes, encontra cada vez mais dificuldade de ser praticado por falta de espaços adequados.

Aqui vale ressaltar que, por crianças, entende-se a pessoa até 12 (doze) anos incompletos, e por adolescentes a de 12 (doze) a 18 (dezoito) anos (BRASIL, 1990).

Uma alternativa que tem surgido à falta de espaço para a prática de educação física e esportes nas escolas que não têm estrutura são os projetos sociais esportivos (PSE), ou projetos socioesportivos, que normalmente são desenvolvidos no contraturno escolar, mediante convênios e/ou parcerias entre escolas e outras instituições públicas e/ou privadas, ou mesmo pela implementação de políticas públicas nesse direcionamento. Um exemplo de política pública voltada para a prática de atividade física e esporte para crianças e adolescentes em situação de vulnerabilidade social é o Programa Forças no Esporte (PROFESP), desenvolvido dentro das Organizações Militares (OM) das Forças Armadas (FFAA), que é uma vertente do Programa Segundo Tempo (PST), do governo federal.

Como o desenvolvimento de políticas públicas ligadas ao desenvolvimento de programas/projetos sociais esportivos tem sido utilizado para compensar a problemática da falta de infraestrutura para a prática de atividade física e esporte nas escolas, este estudo teve por objetivo analisar a contribuição do Profesp para a inclusão social e o desenvolvimento esportivo do Brasil, através do oferecimento de infraestrutura adequada à prática de atividades físicas e esportes em grande parte do território 
nacional.

\section{Métodos}

O presente estudo é uma pesquisa mista em que os componentes quantitativos e qualitativos se complementam, fazendo uma análise paralela (YIN, 2016).

Tal escolha se deu devido à grande complexidade existente entre as relações interpessoais, nas organizações, nos valores dos adolescentes, para que seja utilizado um único enfoque, mostrando que a pesquisa precisa ser multidisciplinar e multimetódica. Foi feita uma integração sistemática dos métodos qualitativo e quantitativo visando obter um panorama mais completo do fenômeno (SAMPIERI; COLLADO; LUCIO, 2013).

Buscamos quantificar informações de forma que elas auxiliassem na identificação dos principais dados que nos dessem o panorama atual do Profesp. Além disso, complementamos os dados quantitativos com as visões, opiniões, críticas e sugestões de pessoas diretamente envolvidas na condução das atividades do programa nos seus polos espalhados por todo o Brasil, para dar mais qualidade à argumentação e discussão dos resultados obtidos.

Participaram os coordenadores do Profesp em todo o território nacional no ano de 2018, voluntários a participar das entrevistas e/ou responder aos questionários.

Considerando que existem 160 (cento e sessenta) organizações militares (OM) do Exército, da Marinha ou da Aeronáutica que desenvolvem o Profesp (DE PAULA, 2018), conseguimos e-mail de 226 (duzentos e vinte e seis) coordenadores e professores diretamente envolvidos com o Profesp, para os quais enviamos questionários, dos quais obtivemos um retorno de 82 (oitenta e dois).

Além dos questionários, foram realizadas entrevistas com três coordenadores de $\mathrm{OM}$ da cidade do Rio de Janeiro, sendo um de cada Força Armada (Marinha do Brasil, Exército Brasileiro e Força Aérea Brasileira).

Foi realizada análise documental para melhor embasamento sobre os assuntos relacionados com o tema, como exclusão social, programas sociais esportivos, inclusão social através do esporte, iniciação esportiva e o desenvolvimento esportivo, Programa Segundo Tempo, Programa Forças no Esporte, as Forças Armadas e o esporte. Foram analisados artigos científicos, livros, documentos da ONU, Unesco, Comissão Desportiva Militar do Brasil (CDMB), MD, PubMed, Scielo, Google Acadêmico, páginas de projetos socioesportivos na internet e outros.

O questionário e o roteiro de entrevista propostos foram validados em estudo piloto, realizado no polo do Profesp no Centro de Preparação de Oficiais da Reserva do Rio de Janeiro (CPOR-RJ), onde, após serem realizados, foram aprimorados conforme as observações apresentadas pelos participantes voluntários daquele polo, com nova redação, inclusão e exclusão de perguntas. 
As informações obtidas na análise documental, questionários e entrevistas foram analisadas separadamente e, posteriormente, trianguladas visando dar maior confiabilidade ao estudo, com uma análise mais completa das opiniões, atividades, processos e resultados do Profesp, como pode ser constatado no capítulo de apresentação e discussão dos resultados.

Obviamente alguns dados obtidos ficaram fora da pesquisa, sendo que os critérios de exclusão iniciais foram a falta de relacionamento com o tema do estudo ou a saturação dos dados, evitando-se qualquer tipo de tendenciosidade, buscando que a pesquisa seja sempre honesta, precisa e justa (Yin, 2016).

Ainda segundo Yin (2016), todo estudo, como este, com participação de humanos, exige prévia aprovação de um comitê institucional de ética (CIE).

Houve a aplicação de modos de proteção às pessoas, o que, neste caso, foram o respeito no tratamento de todos, a garantia de sigilo de identidade e confidencialidade a todos os participantes que responderam a questionários ou participaram de entrevistas. Além disso, todos preencheram o Termo de Consentimento Livre e Esclarecido (TCLE) antes de sua participação, onde o participante indicou que era voluntário e entendia o propósito e a natureza da pesquisa.

\section{Projetos Sociais Esportivos}

Inúmeros estudiosos e instituições no Brasil e no mundo publicam sobre Projetos Sociais Esportivos (PSE), apontando características, pontos positivos e negativos, facilitadores e barreiras para a execução, entre muitos outros aspectos que visam a analisar sua realização e contribuir para que os projetos sejam aprimorados, priorizando e potencializando a formação cidadã completa das crianças e adolescentes participantes, além de contribuírem para a inclusão social desse público, em especial os que vivem em situação de vulnerabilidade social, ou seja, que estão à margem da sociedade, passando por processo de exclusão.

Segundo a Unesco (2013), os programas de educação física e esporte devem trazer conteúdo e ser desenvolvidos de maneira que auxiliem na criação de hábitos e padrões de comportamento que indiquem o pleno desenvolvimento do indivíduo. Devem-se buscar atividades que apresentem maior valor educacional, focando na formação da criança e do jovem.

O profissional de educação física dedicado e comprometido, que entende a importância do esporte para a transformação social, favorece o desenvolvimento de características como respeito, solidariedade, fraternidade, honestidade e responsabilidade, que são valores inseridos no contexto do ser humano integral. Programas sérios e compromissados com o bem-estar da sociedade contribuem para trazer felicidade e uma perspectiva positiva à vida dos participantes (SANCHES FILHO; BARRETO, 2010).

Os programas de educação física e esporte devem contar com instalações e equipamentos adequados e suficientes para que haja uma participação massiva e segura, seja no 
horário escolar ou no contraturno, exigindo de todos os agentes (governos, autoridades públicas e privadas) a união de esforços e o correto planejamento para a execução dos programas (Unesco, 2013).

A falta de infraestrutura esportiva nas escolas faz com que o direito fundamental de crianças e adolescentes à prática de atividade física e esporte não seja respeitado. De um total de 144,5 mil escolas de ensino fundamental e médio existentes no Brasil (FORTUNA, 2018), apenas $0,58 \%$ (838 escolas) foram consideradas escolas ativas, que são as que possuem estrutura e distribuição de tempo adequadas à prática das atividades físicas, no último relatório do PNUD, da ONU (GAZETAONLINE, 2017). É um número muito pequeno de escolas em condições de garantir às crianças e adolescentes o seu direito à prática de atividade física e esporte. Esse número se torna ainda mais relevante quando vemos que, das 116 mil escolas de ensino fundamental, 34,5\% (40 mil escolas) possuem instalações esportivas, e das 28,5 mil instituições de ensino médio, 39,3\% (11,2 mil escolas) possuem instalações esportivas (THOMÉ, 2017), o que nos mostra que mesmo muitas escolas que, tendo estrutura, ou não fazem sua adequada manutenção para que estejam em condições de utilização ou simplesmente não destinam tempo para a prática de atividade física e esporte.

Vários estudos como os de De Castro e SOUZA (2011), Souza, Castro e Vialich (2012) e Souza, Castro e Mezzadri (2012) concordam em que a participação de crianças e adolescentes em projetos sociais esportivos apresenta muitos facilitadores e barreiras. Entre os facilitadores temos: a) o fato de o projeto ser percebido como um "porto seguro", pois afasta as crianças das ruas, drogas, violência e criminalidade, protegendo-as da marginalidade; b) acesso à prática desportiva; c) incentivo por parte dos pais e/ou responsáveis; e d) oferta de oportunidades educacionais. Entre as barreiras encontradas, temos: a) a falta de segurança nos bairros onde as crianças moram e/ou o projeto é desenvolvido, principalmente no trajeto até o local das atividades devido à violência na região que pode vir a vitimar os participantes ou leválos a abandonar o programa; b) obrigações domésticas que são impostas a algumas crianças e adolescentes; c) falta de participação de alguns pais e/ou responsáveis; e d) o clima, dependendo da região, pois o frio ou calor excessivo, assim como a chuva, podem atrapalhar as atividades em locais que não haja proteção. Como muitos projetos trabalham com voluntários, isso pode se transformar em problema, pois eles podem não ter o mesmo comprometimento e não ter a formação pedagógica adequada. Alguns fatores como esses interferem na implementação de programas, assim como os materiais disponíveis para a execução e a participação ou não dos pais/responsáveis.

Em 1978, a Unesco divulgou a Carta Internacional da Educação Física e do Esporte, em que coloca o esporte e a educação física a serviço do progresso humano, promovendo o seu desenvolvimento. Dentre os principais pontos da Carta, destaco: para o desenvolvimento da personalidade, a educação física e o esporte contribuem de forma essencial, devendo ser 
considerados direitos fundamentais o acesso a tais práticas, em que se busca desenvolver aptidões físicas, morais e intelectuais. Para o indivíduo, elas contribuem para melhora e manutenção da saúde, sendo atividade de lazer saudável, contribuindo para a diminuição e superação de fatores causadores de stress. Para a sociedade, elas contribuem para o aprimoramento das relações sociais (UNESCO, 2013).

A Unesco (2013) mostrou que por meio da prática esportiva podem-se reforçar valores positivos como o companheirismo, o espírito de equipe e o fairplay, dentre outros. Com isso o esporte e a educação física contribuem para a socialização e desenvolvimento humano de crianças e adolescentes. Além dos valores, também contribuem para o ensinamento de regras de convivência e respeito aos demais. Outro benefício é no que tange à saúde, já que com a prática esportiva há estímulo para se obter um estilo de vida mais saudável, contribuindo inclusive para a diminuição de gastos públicos com saúde e segurança pública. Além de ser bom para o próprio indivíduo no que se refere aos aspectos de desenvolvimento humano e social, o esporte também é capaz de reunir em torno da prática esportiva pessoas de raças, credos e crenças totalmente diferentes.

Segundo Osborne e dos Santos (2015), as quatro horas de ensino ofertadas pela maioria das escolas não são suficientes para atender as necessidades dos jovens. Uma dificuldade para a solução dessa situação é a falta de continuidade dos projetos educacionais governamentais, que normalmente são deixados de lado por novos governos, inviabilizando, assim, a efetivação de projetos significativos. Os autores mostraram a preocupação de que haja a realização de projetos esportivos sem bases educacionais, apenas utilizando o esporte como ferramenta política e sem contribuir para o desenvolvimento do povo.

Em seu estudo sobre competitividade e inclusão social por meio do esporte, Azevedo e Gomes Filho(2011) mostram que as críticas à busca obsessiva pelo rendimento em detrimento de outros valores humanos existem e são corretas, porém todo esporte deve apresentar "testes artificiais" aos participantes que envolvam o desempenho de habilidades físicas. Além disso, como os esportes de alto rendimento são regulados por ligas e federações, podem vir a representar uma ocupação duradoura no futuro, dependendo do nível de excelência atingido pelo praticante. E os praticantes de modalidades esportivas, sejam elas realizadas por instituição social (sem competição) ou como esporte institucionalizado, saem ganhando de algum modo, seja em saúde e qualidade de vida, formação cidadã, seja como opção de ocupação ou de carreira.

\section{O Exército Brasileiro e o Esporte - o caminho até o Profesp}

Há uma íntima ligação entre o esporte e a atividade militar, sendo o primeiro visto como a forma mais econômica e próxima para se imitar a dura realidade do combate (tanto pelo lado fisiológico, quanto físico e emocional) no dia a dia da caserna (quartéis). Ao treinar seus 
soldados usando o esporte, fazendo-os buscar o seu melhor atuando sozinhos ou em grupos nas quadras, pistas, piscinas ou campos, os chefes militares também estão preparando sua tropa para buscar superar desafios em combates reais (RIBAS, 2007).

Em sua palestra para o Curso de Bacharel em Educação Física da Escola de Educação Física do Exército (EsEFEx), o historiador do Centro de Capacitação Física do Exército (CCFEX), coronel (Cel.) R/1 Mauro Secco, falou sobre o envolvimento histórico do Exército Brasileiro (EB) com as atividade físicas e o esporte, que remonta aos idos de 1915 e permanece até os dias atuais, como mostra a linha do tempo abaixo:

\section{LINHA DO TEMPO}

1915 - Criação da Liga Militar de "Foot-ball" (LMF).

1920 - Transformação da LMF em Liga de "Sports" do Exército (LSE).

1922 - Criação do Centro Militar de Educação Física (CMEF), na Vila Militar-R.

1930 - Transferência do CMEF para a Fortaleza de Săo João.

1933 - Transformação do CMEF em Escola de Educação Fisica do Exército (EsEFEx).

1947 - Criação do Departamento de Desportos do Exército (DDE), em substituição à LSE.

1956 - Transformação do DDE em Comissão de Desportos do Exército (CDE).

1990 - Criação do CCFEx/FSJ: EsEFEx, CDE, Bia Art Cos e núcleo do IPCFEx.

1997 - Criação do Instituto de Pesquisa da Capacitação Fisica do Exército (IPCFEx).

2002 - Transformaçåo do CCFEx/FSJ em Diretoria de Pesquisa e Estudos de Pessoal (DPEP).

2007 - Incorporaçåo da Escola de Equitaçăo do Exécito (EsEqEx).

2012 - Transformação da DPEP em CCFEX/FSJ.

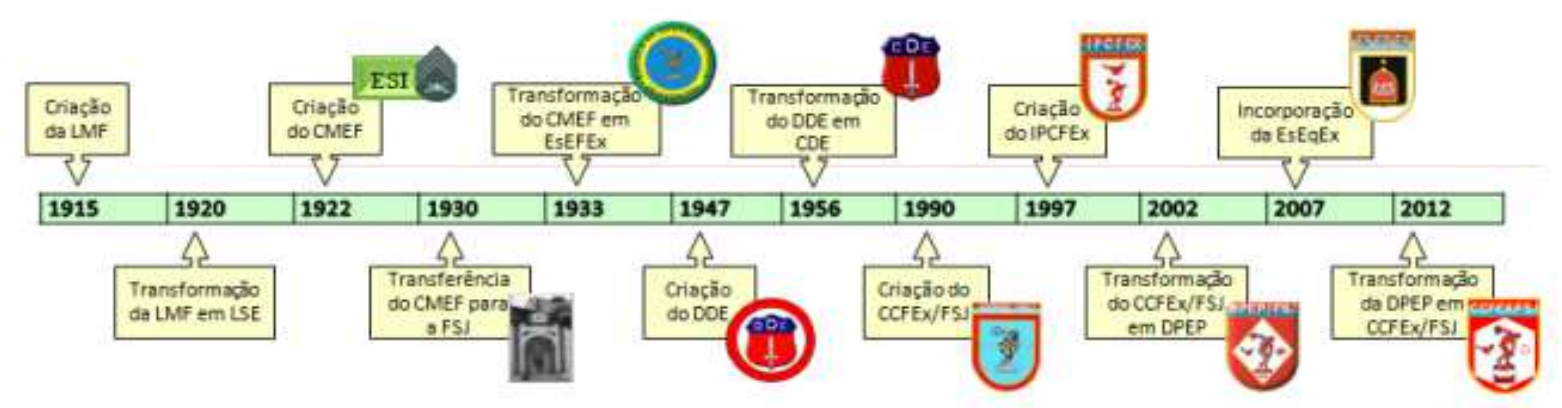

Figura 1 - Linha do Tempo do Esporte no Exército Brasileiro

Fonte: Mauro Secco

Segundo Secco (2017), em 1929 foi formada, no Centro Militar de Educação Física (CMEF), embrião da EsEFEx, a primeira turma de militares e civis diplomados em educação física no Brasil, no Curso Provisório de Educação Física. A partir de 1930, já sediada na Fortaleza de São João, foram reorganizados e reiniciados regularmente os cursos de Instrutor e de Monitor de Educação Física, de Especialização em Medicina e Mestre D'Armas, mostrando a vocação da EsEFEx para influenciar a educação física no Brasil e no mundo, com a presença de alunos do exterior.

Em 1936 a EsEFEx organizou sua primeira "colônia de férias", atividade precursora do esporte recreativo como inclusão social, a qual funciona até os dias atuais, sendo a mais antiga do país, recebendo centenas de crianças, inclusive portadoras de necessidades especiais. 


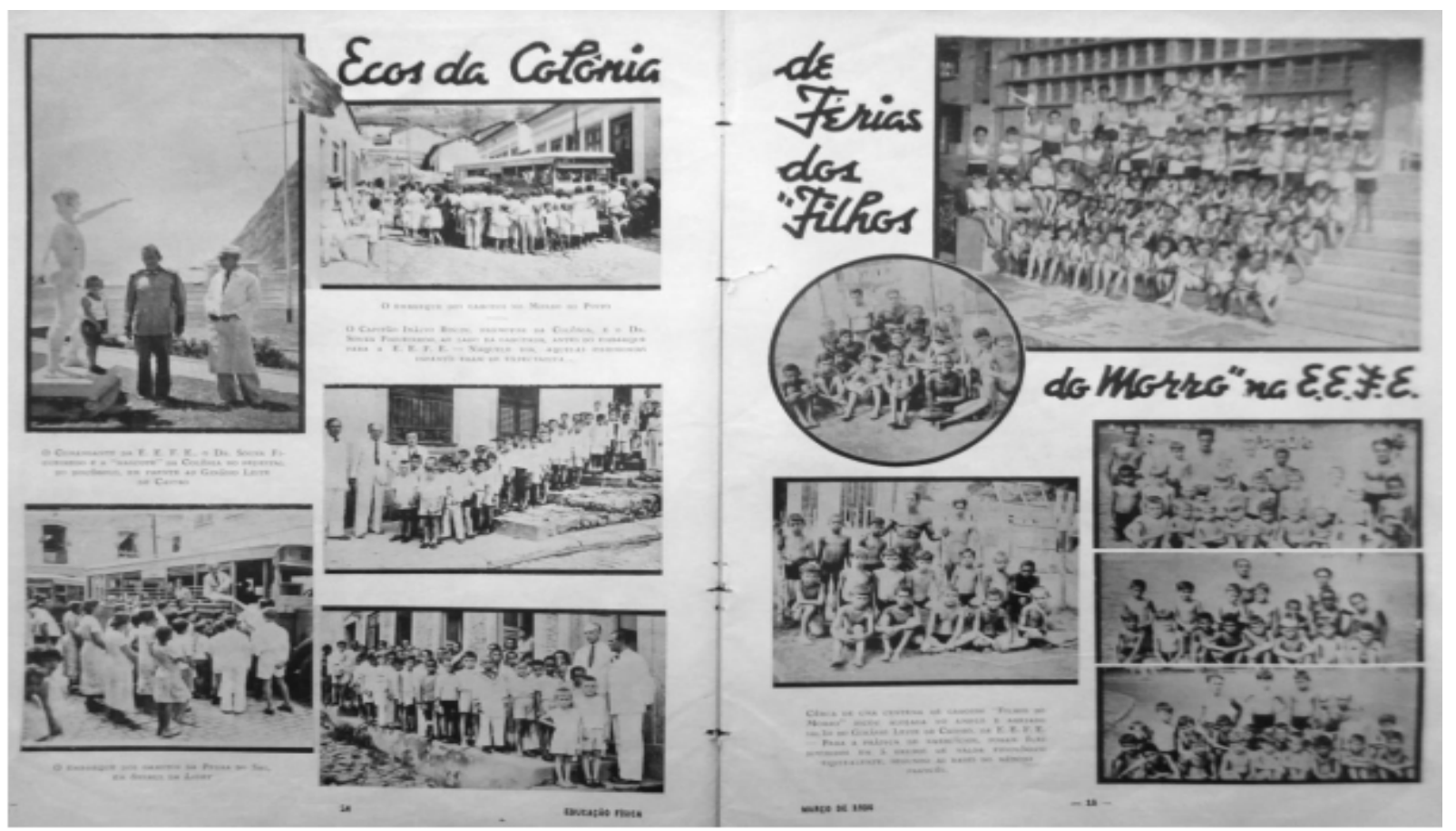

A "Colônia de Férias" iniciada em 1936.

Figura $2-1^{\text {a }}$ Colônia de Férias da Escola de Educação Física do Exército, 1936 Fonte: Mauro Secco

Ainda sobre o esporte e atividade física voltados para crianças e adolescentes, o EB dá grande ênfase à educação física nos seus colégios militares, realizando, inclusive, os "Jogos da Amizade do Sistema Colégio Militar do Brasil", competição anual que promove o congraçamento desses colégios por meio do esporte, visando harmonizar a prática esportiva, valorizando o caráter educativo do esporte, desenvolvendo atributos da área afetiva (respeito, dedicação, companheirismo, espírito de corpo, dentre outros) que são necessários à formação do cidadão, além de estimular o desempenho escolar (SECCO, 2017). 


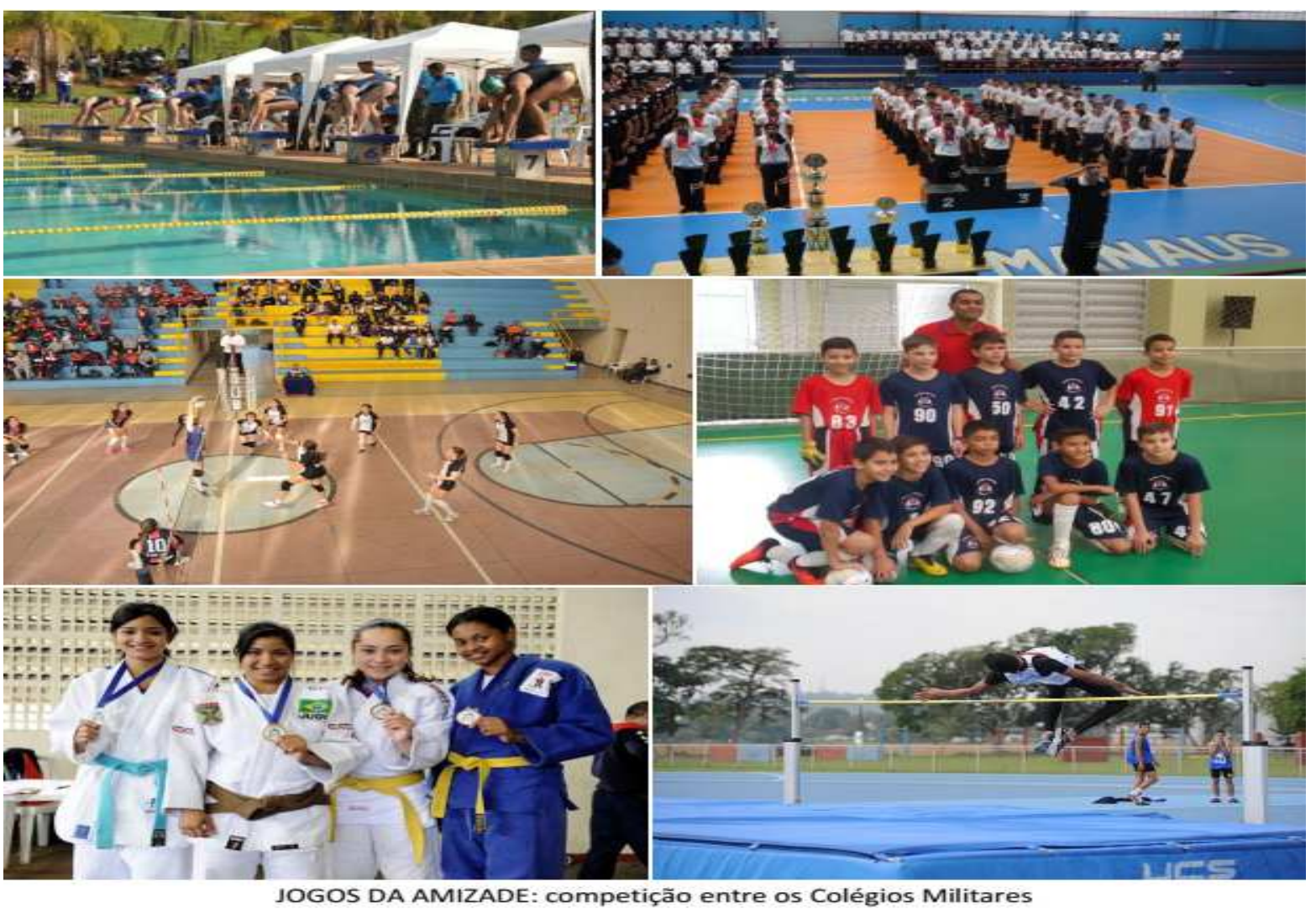

Figura 3 - Jogos da Amizade do Sistema Colégio Militar do Brasil Fonte: Mauro Secco

Aumentando ainda mais sua ligação com a atividade física, em 2013 as FFAA e o EB aderiram à execução de projetos sociais esportivos dentro de suas organizações militares (OM) por meio do Programa Forças no Esporte (PROFESP), a vertente do Programa Segundo Tempo (PST) do governo federal, desenvolvida pelo Ministério da Defesa (MD).

Esse programa foi normatizado através da Portaria Normativa Interministerial $\mathrm{N}^{\circ}$ 2.203/MD/ME, de 26 de julho de 2013, publicada no Diário Oficial da União (D.O.U.) n ${ }^{\circ}$ 147, Seção 1 , de $1^{\circ}$ de agosto de 2013, que prevê, dentre outras coisas:

Art. $1^{\text {o }}$ - Instituir a formalização do Programa Forças no Esporte (Profesp), com a finalidade de proporcionar atividades esportivas e físicas saudáveis para a comunidade em geral, priorizando o atendimento de crianças, adolescentes e jovens em estado de vulnerabilidade social, nos termos desta Portaria Normativa Interministerial.

$\S 1^{\circ}-(\ldots)$.

$\S 2^{\circ}-(\ldots)$.

$\S 3^{\circ}$ - A contribuição para a melhoria da qualidade de vida, o acesso à prática esportiva educacional orientada, bem como a descoberta, o desenvolvimento e o acompanhamento de novos talentos esportivos, terão como suporte a utilização das instalações esportivas, dos equipamentos esportivos, da infraestrutura e da logística disponibilizados pelas Organizações Militares (OM) das Forças Armadas que aderirem ao Programa, em parceria com a comunidade, iniciativa privada, demais segmentos do poder público, terceiro setor e o sistema esportivo organizado civil e militar.

Art. $2^{\circ}$ - As OM participantes do Profesp deverão: 
I - propor campanhas promocionais, estratégias de marketing e ações ajustadas às necessidades das comunidades a serem atendidas;

II - identificar as necessidades, existentes e potenciais, das comunidades próximas;

III - monitorar o desenvolvimento do Programa na localidade onde for implantado, por meio de análises estatísticas, tendências e perfis;

IV - divulgar a existência do Programa como ferramenta para geração de oportunidades para crianças e jovens carentes;

$\mathrm{V}$ - divulgar os eventos esportivos realizados na $\mathrm{OM}$ ou aqueles dos quais irá participar;

VI - trabalhar em conjunto com terceiros envolvidos na promoção e captação de investimentos destinados ao desenvolvimento do esporte; e

VII - elaborar em conformidade com as diretrizes e metodologias do Programa Segundo Tempo (PST), seus projetos e respectivos planos de trabalho (BRASIL, 2013, p. 10).

O Profesp busca a educação integral, fazendo uma sintonia entre as atividades e a vida, possibilidades, necessidades e interesses dos alunos. Atuando no contraturno escolar dentro de instalações militares com boa infraestrutura esportiva, o programa busca o desenvolvimento físico, intelectual, cultural, humanístico, artístico e sanitário. Ele estimula a responsabilidade das crianças e adolescentes, lembrando-as dos seus direitos e deveres, fazendo-os cidadãos criativos, participantes e empreendedores, que ajudarão o Brasil e a humanidade na promoção da paz e da fraternidade e na busca da justiça e da solidariedade. Um exemplo é o polo da Base Aérea de Natal, que, em seu relatório no final do ano de 2015, apontou como resultados alcançados a diminuição da violência familiar, fortalecimento da consciência ambiental, aumento do interesse pelas atividades esportivas, melhora no rendimento pedagógico, progresso no convívio e na integração social, melhora das condições de saúde e recuperação da autoestima (JANUZZI; GUEDES, 2015).

Atualmente o Profesp está presente em 111 municípios, 26 estados e no Distrito Federal, sendo executado em 160 organizações militares das FFAA, atendendo a 23.731 crianças e adolescentes de 6 a 17 anos de idade (DE PAULA, 2018). Ele é uma parceria interministerial envolvendo, além do MD (responsável pela coordenação das atividades nas OM, além de atendimento médico, odontológico e assistência social, transporte e monitores), o Ministério do Esporte (ME) e o Ministério do Desenvolvimento Social e Agrário (MDSA). O ME paga os professores e estagiários enquanto que o MDSA é o responsável pelos custos de alimentação dos participantes (BRASIL, 2018).

Em minha opinião, os números do Profesp ainda são pequenos em relação ao potencial do programa, se levada em consideração a quantidade de organizações militares das Forças Armadas espalhadas por todo o Brasil. Vale lembrar também que o programa é uma vertente que serve de apoio e complementação do Programa Segundo Tempo. Acredito que os dois programas podem e devem ser ampliados para que possam atingir a quase totalidade das crianças brasileiras, para que, assim, o Estado cumpra seu papel constitucional de fazer valer para as crianças e adolescentes do país o seu direito inalienável de acesso à educação física e ao 
esporte, principalmente nos locais onde as escolas não possuem, nem tem como possuir, por falta de espaço, estruturas compatíveis para a adequada prática de atividades físicas. Essa última realidade, a da falta de instalações esportivas adequadas, faz com que a ampliação de programas como estes, PST e Profesp, seja de suma importância para o combate ao sedentarismo, com a inclusão social e o desenvolvimento completo das crianças e adolescentes brasileiras. Tais programas deveriam ter caráter permanente nas regiões onde não há como as escolas oferecerem educação física e esporte para todos.

Segundo o Portal Brasil (2018) o programa promove o desenvolvimento integral dos jovens, além de democratizar o acesso à cultura do esporte através de atividades de lazer, atividades esportivas educacionais e atividades complementares (ações cívico-sociais, reforço escolar, alimentação saudável e de qualidade, orientações de civismo, de cidadania, palestras e campanhas educativas, além de desenvolvimento de habilidades profissionais). Pelo trabalho desenvolvido no Profesp, o programa concorreu em 2016 ao prêmio internacional Peace \& Sport Award, em Mônaco, que foi criado em 2008 pela "Peace and Sport, L'Organization pour la Paix par le Sport”, agraciando instituições e pessoas que tenham contribuído para o diálogo, a estabilidade social e o desenvolvimento da paz no mundo por meio do esporte.

\section{Apresentação e discussão dos resultados}

Através da revisão da literatura, principalmente, buscamos identificar em diversas análises, as características marcantes de vários programas/projetos sociais esportivos (PSE) realizados por entes privados e/ou desenvolvidos a partir de políticas públicas governamentais. Os questionários e entrevistas visaram analisar, além dos aspectos já observados na revisão da literatura, o panorama atual do Profesp em todo o Brasil. Abordamos os resultados obtidos após a aplicação dos questionários, relacionando suas respostas com as respostas das entrevistas e com a revisão da literatura. Eles foram enviados aos coordenadores do Profesp das 160 organizações militares (OMs) das FFAA em que há polos do programa (para se ter ideia, somente o Exército Brasileiro possui $648 \mathrm{OMs}$, mostrando que o programa ainda pode ser difundido e implementado em muitos outros quartéis das FFAA, pois o percentual ativo ainda é pequeno. 


\section{Quantos professores(as) / orientadores (as) trabalham em seu polo? \\ 82 responses}

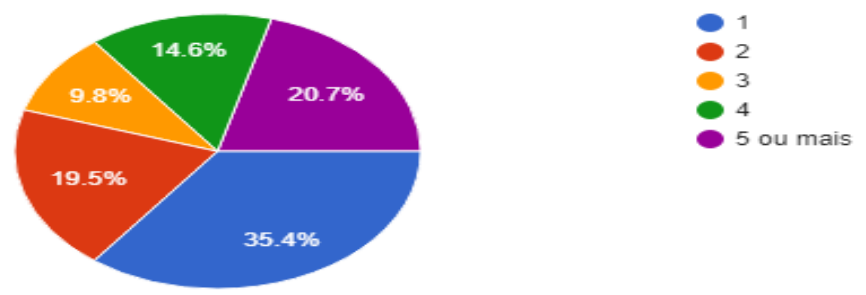

Figura $4-1^{\circ}$ questionamento

Foi observado que mais da metade das OMs (54,9\%) possuem apenas um ou dois professores para orientar as atividades das crianças. Pelas respostas das entrevistas, foi observado que as OMs hoje enfrentam uma grande dificuldade administrativa para contratação de pessoal capacitado (professores): "Atualmente os militares conduzem as atividades, pois existem entraves administrativos que nos impedem de contratar professores autônomos", afirmou o entrevistado 3. Assim, uma saída é a execução de parcerias para, a partir delas, contratar os profissionais das diversas áreas: "Como não conseguimos contratar diretamente os professores, buscamos parcerias com instituições e empresas, expondo suas marcas nos uniformes e locais de atividades em troca da contratação dos profissionais pelos parceiros", afirmou o entrevistado 2. Essas questões administrativas, com soluções diferentes em cada Força Armada, fazem com que não haja uma padronização de execução do Profesp em todos os polos. Como resultado, há prejuízo aos participantes, já que o núcleo que não pode contratar e não consegue realizar parcerias não monta equipe de trabalho multidisciplinar, com profissionais como pedagogos(as), nutricionistas, assistentes sociais, psicólogos(as), profissionais de educação física, dentre outros.

$\mathrm{O}$ ideal é que esses entraves administrativos que Exército e Força Aérea vêm apresentando para a contratação direta de profissionais sejam solucionados. Assim, os núcleos, ao receber recurso dos ministérios para realizar a contratação de todos os profissionais necessários, poderão fazê-lo e prestar o melhor apoio possível às crianças e adolescentes participantes do programa. 


\section{Quantos estagiários(as) trabalham em seu polo? \\ 82 responses}

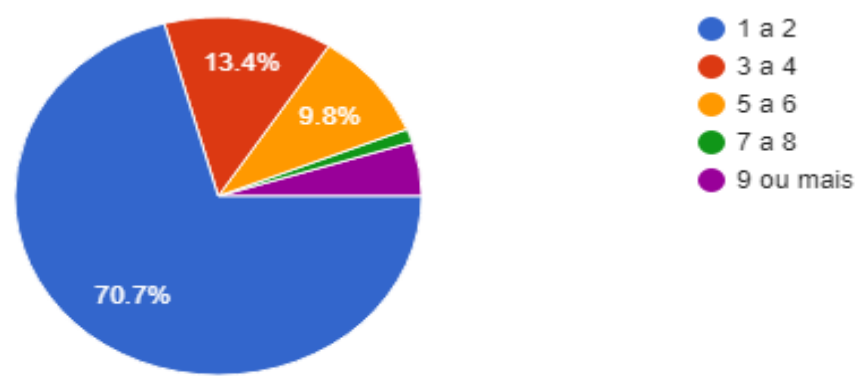

Figura $5-2^{\circ}$ questionamento

Observou-se que 70,7\% das OMs não possuem mais que 2 (dois) estagiários para apoiar as atividades. Esse baixo contingente ocorre porque, apesar de contar como estágio para as universidades, ele não é remunerado, não há auxílio transporte ou qualquer outro incentivo, principalmente financeiro (devidos aos entraves administrativos mencionados no questionamento anterior), que atraia os estudantes para realizar essa atividade extracurricular. Os Ministérios têm de apoiar os núcleos com recursos financeiros suficientes para a remuneração dos estagiários e pagamento de auxílio-transporte a eles, para ser mais atrativo, revertendo em benefício direto aos participantes, além de auxiliar na busca pela solução das barreiras administrativas que inviabilizam a contratação direta.

\section{Em qual região do Brasil se localiza o polo em que o senhor(a) trabalha? 82 responses}

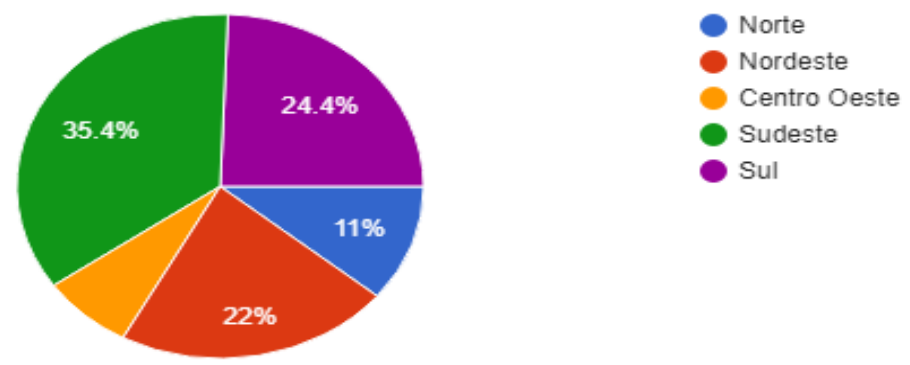

Figura $6-3^{\circ}$ questionamento

A representatividade nacional das respostas ao questionário seguiu percentual muito similar à distribuição das organizações militares que desenvolvem o Profesp pelo Brasil, informada pela CDMB, pois hoje temos $16,9 \%$ dos programas na Região Norte (contra $11 \%$ de retorno), $21,9 \%$ na Região Nordeste (contra $22 \%$ de retorno), $10 \%$ na Região Centro-Oeste 
(contra 7,3\% de retorno), 30\% na Região Sudeste (contra 35,4\% de retorno) e 21,3\% na Região Sul (contra $22 \%$ de retorno). Isso pode indicar que a nossa amostra foi bastante representativa em nível nacional.

\section{O senhor(a) trabalha, no PROFESP, com crianças de qual faixa etária? (marque mais de uma alternativa, se for o caso) \\ 82 responses}

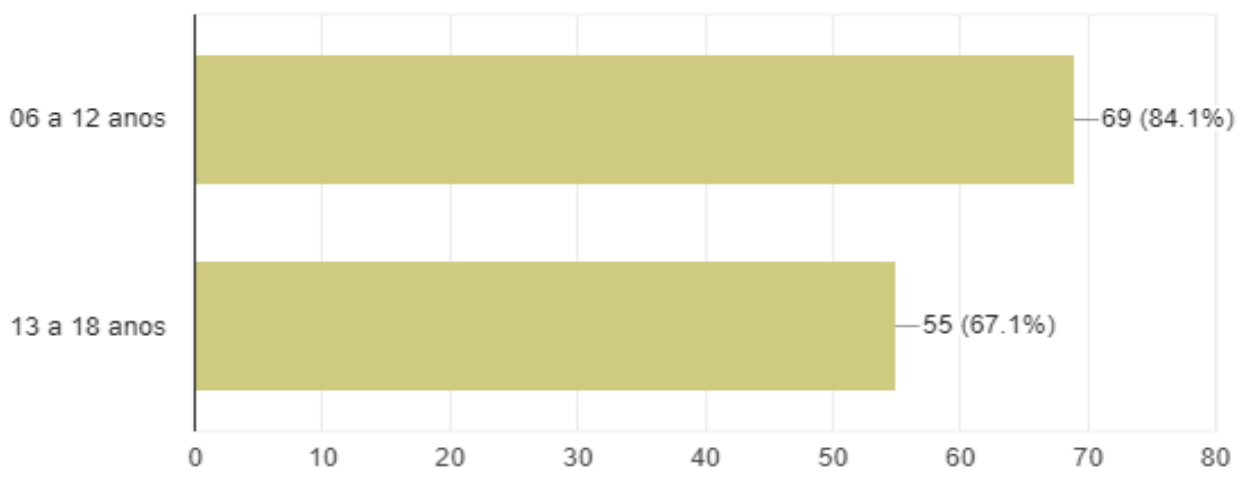

Figura $7-4^{\circ}$ questionamento

Aqui pudemos constatar que os polos em funcionamento abarcam crianças de várias idades, tendo grupos de crianças e grupos de adolescentes. Isso requer que haja uma divisão das atividades para melhor aproveitamento de todos, de acordo com a fase de desenvolvimento de cada um. Assim, a fase de maturação e de desenvolvimento corporal será respeitada, e o aproveitamento da atividade será mais eficiente.

\section{Qual o número de crianças e jovens participantes do PROFESP em seu polo?

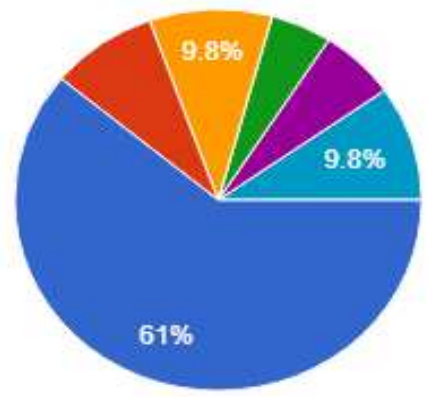

Figura $8-5^{\circ}$ questionamento 
Observou-se que $61 \%$ das OMs trabalham com até 100 participantes. Isso pode ser resultado da falta de capacidade de receber efetivo maior devido à não existência de instalações ou, simplesmente, por falta de estudo prévio de capacidade de alunos para aquele polo do programa, o que pode vir a subestimar o potencial daquela OM quanto ao número de crianças apoiadas. Em todo o Brasil, o Profesp atende a 23.731 crianças e adolescentes de 6 a 18 anos. Segundo informações do IBGE (2017), existem, entre 6 e 14 anos, 26,2 milhões de crianças e adolescentes em escolas, sendo $99,2 \%$ do total existente nesta faixa etária. Isso nos mostra que o programa do MD atualmente alcança um número muito pequeno de crianças e adolescentes. Considerando ainda que existem cerca de 850 organizações militares das Forças Armadas em todo o país (EB, 2018; FAB, 2018; MARINHA, 2018) e que apenas 160 delas, ou seja, cerca de 18,8\%, possuem núcleos do Profesp, dos quais 61\% atendendo somente 100 crianças e adolescentes, observa-se que o programa tem potencial muito maior, tanto em quantidade de núcleos quanto, consequentemente, em quantidade de participantes. Porém, a implantação do Profesp nas OMs não é obrigatória, ficando a mercê do poder discricionário de cada comandante a sua implantação. Como muitos desses responsáveis por OMs não priorizam essa atividade, tendo em vista que a atividade militar é a atividade finalística dos seus quartéis, não o desenvolvimento do Profesp, muitas crianças deixam de ser beneficiadas pelo programa em todo o Brasil.

De quais atividades as crianças e adolescentes do seu polo participam? (marque mais de uma alternativa, se for o caso)

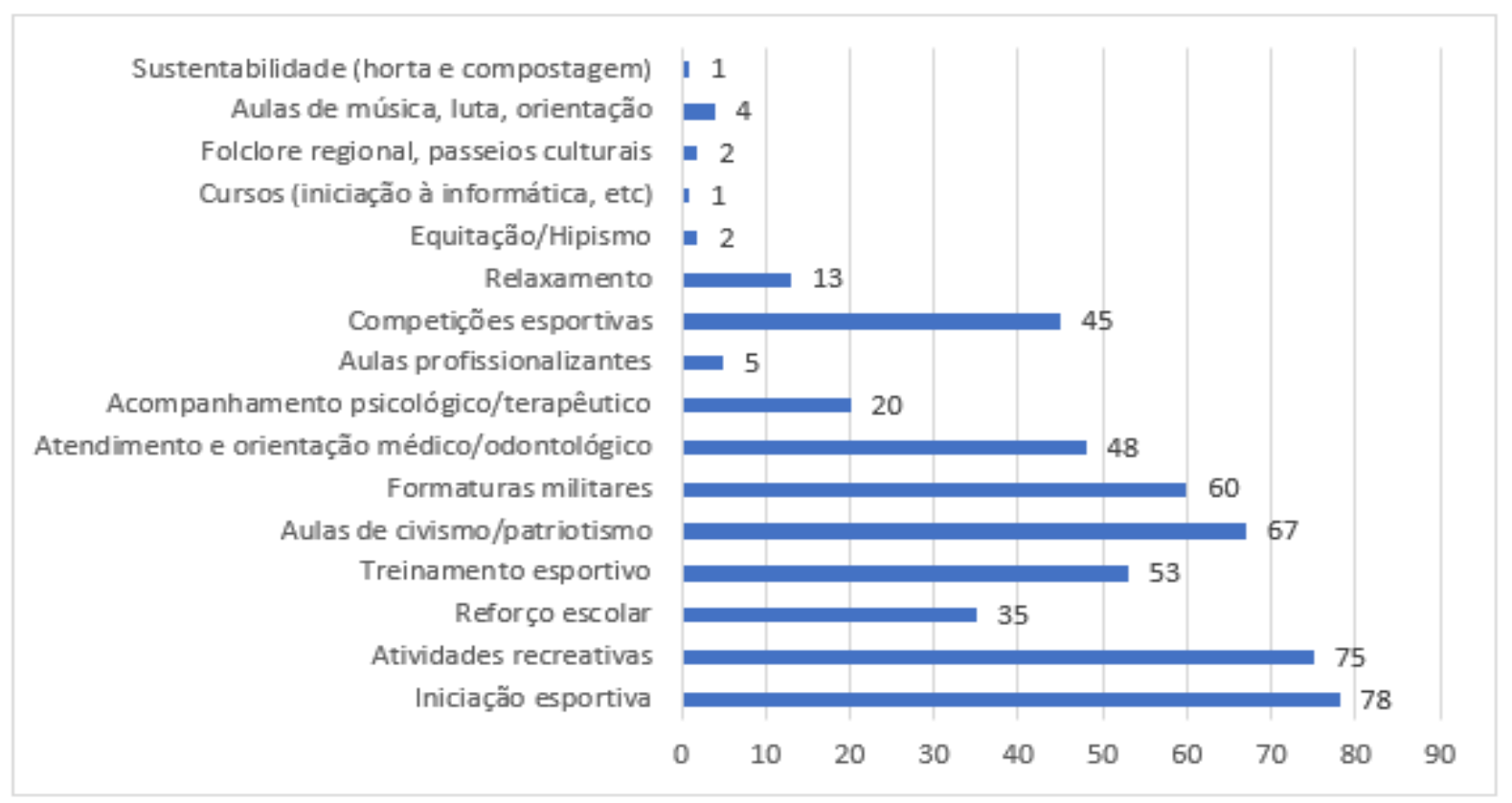

Figura $9-6^{\circ}$ questionamento

Com as respostas a este questionamento, vemos que, de acordo com a criatividade e dedicação dos coordenadores e professores do Profesp, inúmeras atividades podem e são 
oferecidas para contribuir com a formação cidadã do participante do programa. Porém, as atividades que podemos considerar como básicas de quase todos os polos são: iniciação esportiva, atividades recreativas, aulas de civismo/patriotismo, participação em formaturas militares, atendimento e orientação médico/odontológico e o treinamento esportivo. Todas essas atividades são realizadas em pelo menos metade dos polos dos respondentes. Sendo que foi identificado nas entrevistas que os núcleos, em sua maioria, sofrem com entraves administrativos para a contratação de pessoal, o desenvolvimento de atividades variadas fica condicionado à realização de parcerias, em que os parceiros contratam os profissionais, sendo que nem todos os polos conseguem realizar parcerias.
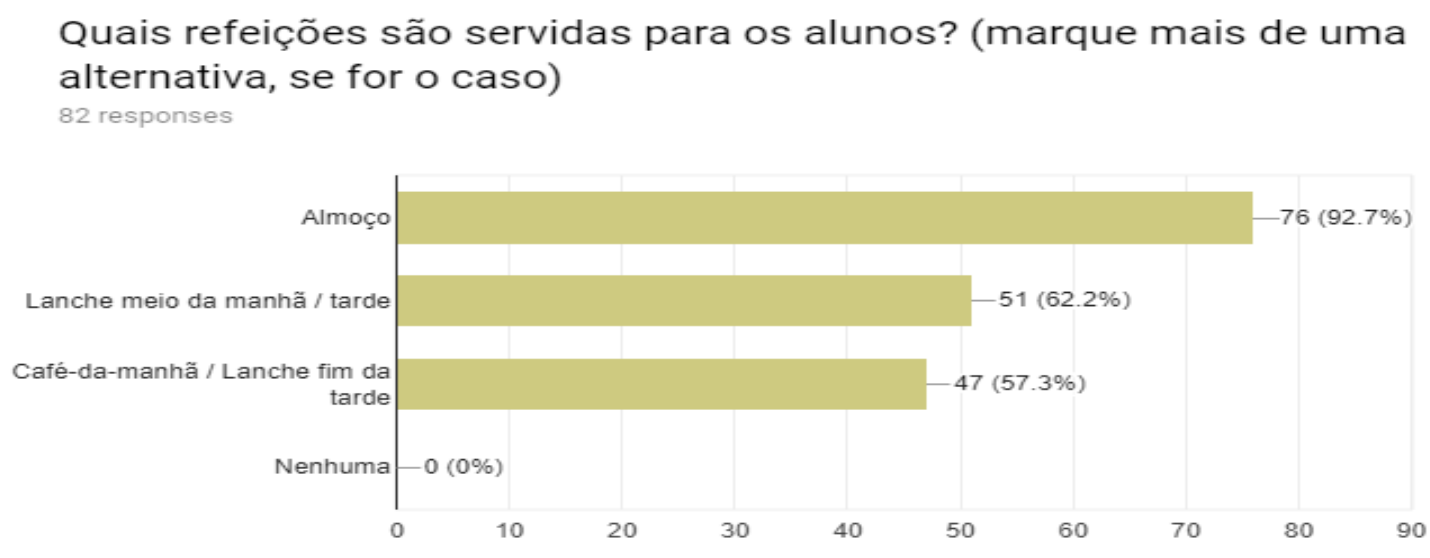

Figura $10-7^{\circ}$ questionamento

\section{Qual a qualidade da alimentação fornecida pela OM sede do programa?} 82 responses

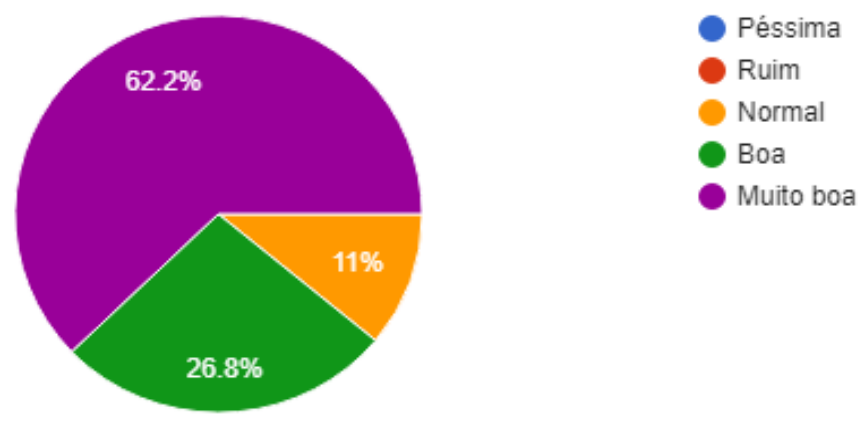

Figura $11-8^{\circ}$ questionamento

Para 62,2\% dos respondentes, a alimentação pode ser considerada de muito bom nível. As OMs que ainda têm uma alimentação considerada boa ou normal devem ser estimuladas a oferecer, a cada dia que passa, uma alimentação melhor para crianças e adolescentes, atingindo 
um padrão muito bom. Todas as refeições devem ser de excelente qualidade. Porém, visando melhorar inicialmente as atividades, sugere-se que o almoço, que é realizado em $92,7 \%$ dos polos, seja paulatinamente aprimorado. Assim, quase que a totalidade dos participantes sentirão os benefícios da melhoria.

Um ponto positivo a ser destacado é o de que nenhum dos respondentes dos questionários considerou a comida ruim ou péssima. Em se tratando de alimentação e sabendose que nem todos possuem o mesmo paladar, as mesmas opiniões, isso é um ponto importante.

\section{Como as crianças e jovens chegam e saem das Organizações Militares $(\mathrm{OM})$ ?
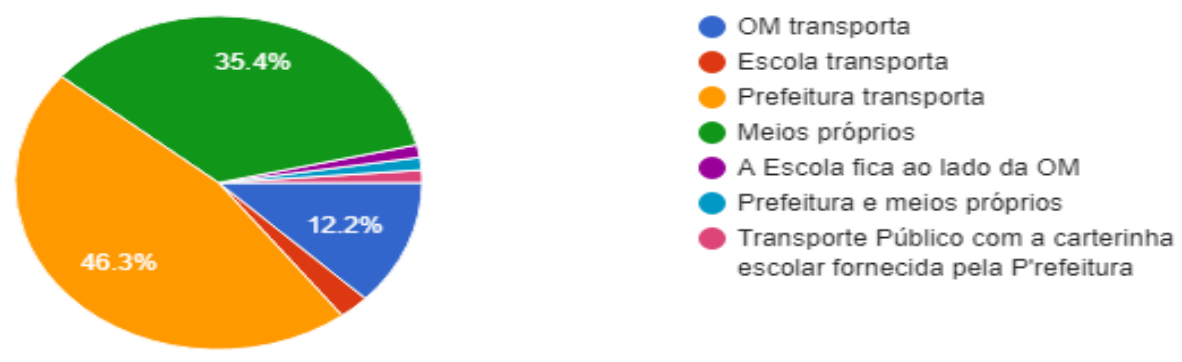

Figura $12-9^{\circ}$ questionamento

Podemos ver que não há uma padronização sobre como os participantes do Profesp se deslocam de suas escolas ou residências para as OMs. Utilizam de meios próprios para esse deslocamento $35,4 \%$ das crianças e adolescentes, o que não vejo como sendo o ideal, pois pode vir a dificultar a participação deles no programa. Outros $62,1 \%$ são levados através de transporte fornecido pelas prefeituras, ou pelas próprias Oms, ou pelas escolas ou recebem carteirinhas que lhes possibilitam o transporte gratuito, o que deveria ser o padrão em todos os polos, ou seja, que o participante não utilizasse recursos próprios para chegar ao local de sua atividade, tendo em vista que estamos falando de uma política pública.

Considero que, para garantir a adesão e permanência do maior número de crianças possível, o ideal é que o transporte lhes seja ofertado, por quaisquer que sejam os meios. 
Há acompanhamento, por parte da coordenação do programa, do rendimento escolar das crianças e jovens participantes? 82 responses

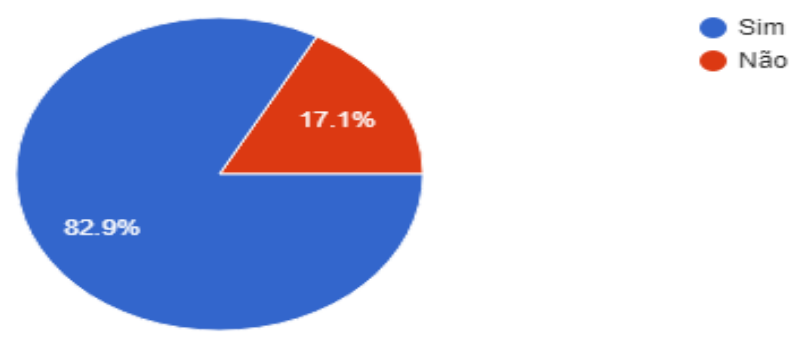

Figura $13-10^{\circ}$ questionamento

Julgamos este fato (F 13) como um aspecto muito positivo para incentivar as crianças e adolescentes a se manterem com bom desempenho escolar. Do total dos respondentes, $82,9 \%$ mostram que seus polos acompanham os resultados escolares dos seus participantes. Nas entrevistas confirmamos esse fato, porém cada OM busca essa informação da maneira que bem deseja, não há padronização.

"Realizamos reunião no início e no encerramento das atividades, quando verificamos com os pais e com os representantes das escolas se houve mudança no comportamento e no rendimento escolar dos nossos jovens", respondeu o entrevistado 2.

Já o entrevistado 1 disse que: "Buscamos realizar reuniões mensais com as escolas e semestrais com os pais, para verificar se houve mudança positiva ou negativa no comportamento dos meninos e meninas em casa e na escola".

Existe desistência de participantes? Em caso positivo, tem conhecimento dos motivos que levam a tais desistências?

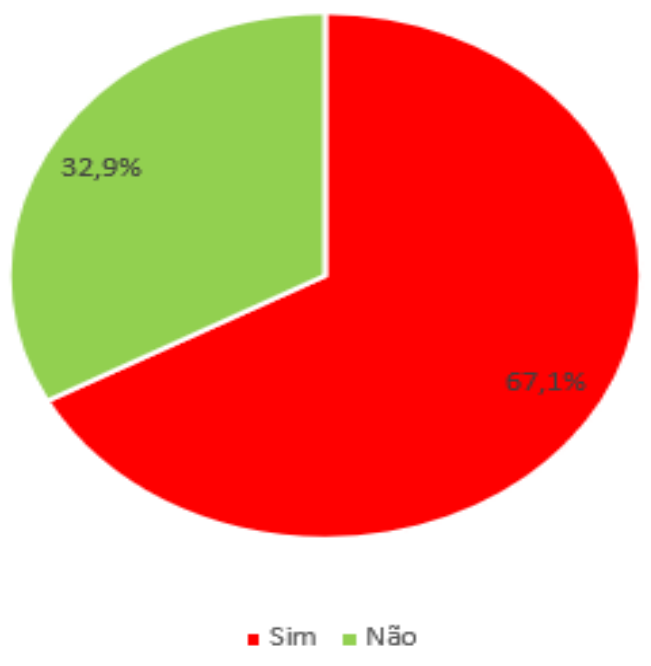

Figura $14-11^{\circ}$ questionamento 
Um dado que chamou a atenção foi de que $67,1 \%$ dos participantes desistem do Profesp, o que considero um índice muito elevado. Para buscar melhorias no programa, devemse conhecer os motivos das desistências.

Segundo os respondentes, somente $2,4 \%$ não têm conhecimento dos motivos de desistência. Os motivos relatados, que levam à evasão do programa costumam ser a mudança de endereço ou de escola, falta de comprometimento do participante e/ou do familiar, necessidade de auxiliar no sustento de casa, mau comportamento e/ou indisciplina por parte do participante que não se adapta à rotina e exigências do programa e a dificuldade de acesso ao programa devido à dificuldade de transporte ou de locomoção dentro das comunidades. Esses motivos se alinham a barreiras existentes em vários outros projetos sociais esportivos, como já citado por de De Castro e Souza (2011), Souza, Castro e Vialich, (2012) e Souza, Castro e Mezzadri(2012).

\section{Qual o tratamento dado às crianças ou jovens que não querem participar das atividades? (marque mais de uma alternativa, se for o caso) 82 responses}

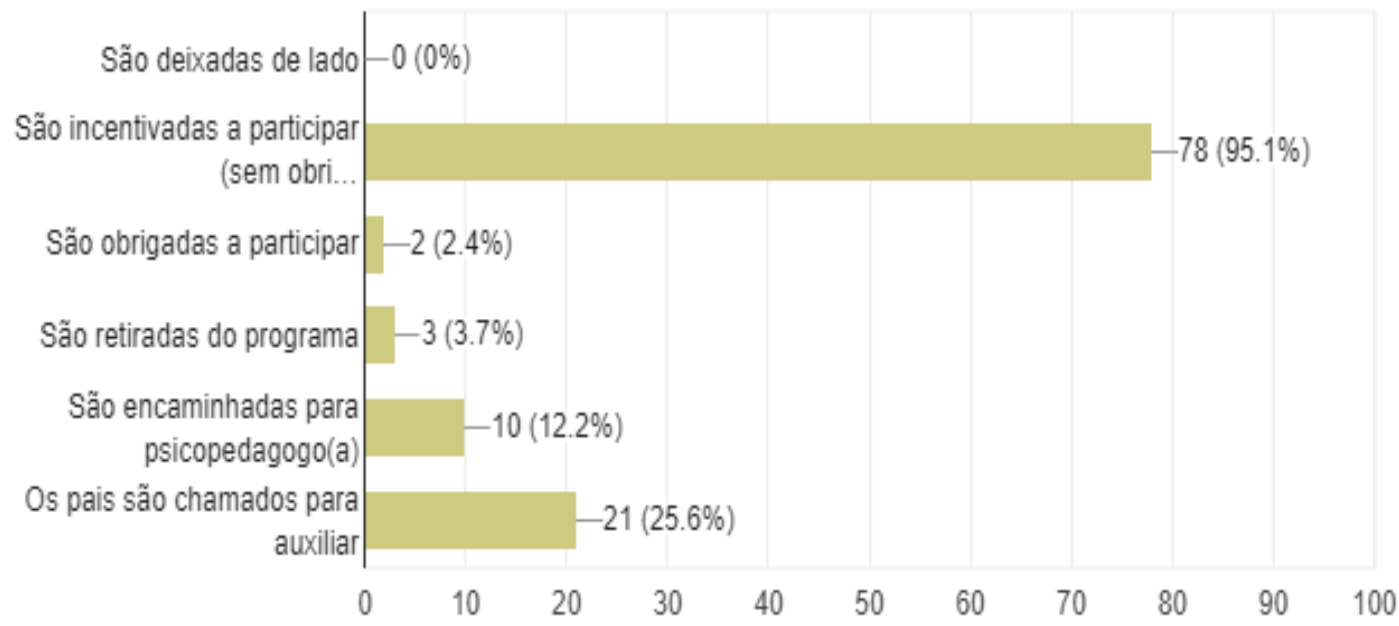

Figura $15-12^{\circ}$ questionamento

Este questionamento nos trouxe um retorno interessante, mostrando que, em 95,1\% dos polos do Profesp respondentes, as crianças e adolescentes são estimuladas ou incentivadas a participar de todas as atividades, mesmo nos momentos em que se recusam, mas sem obrigatoriedade e, em algumas situações $(25,6 \%)$, com a presença dos pais para auxiliar nesse incentivo. Esta última medida pode contribuir sobremaneira para que os que estão isolados voltem a participar das atividades com o restante do grupo, tornando a atividade ainda mais 
inclusiva. Além desta, em alguns polos $(12,2 \%)$ as crianças e adolescentes são encaminhadas a profissional capacitado, psicopedagogo(a) para a tentativa de reincluir o participante.

As atividades esportivas das crianças de 06 a 12 anos são mais voltadas para quais aspectos? (marque mais de uma alternativa, se for o caso) 82 responses

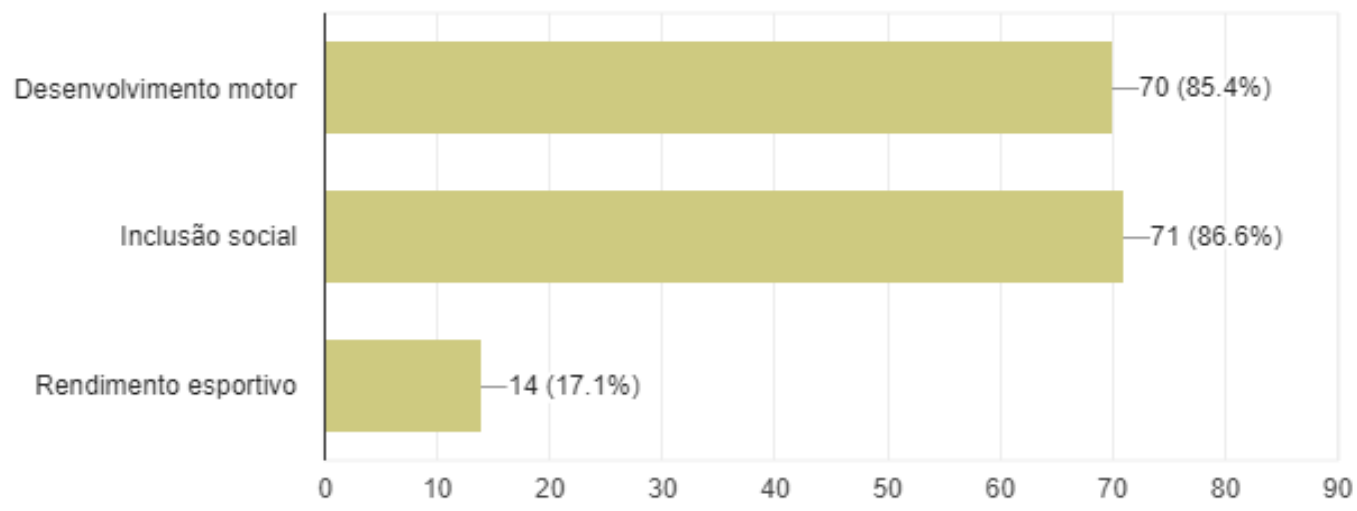

Figura $16-13^{\circ}$ questionamento

As atividades esportivas das crianças de 13 a 18 anos são mais voltadas para quais aspectos? (marque mais de uma alternativa, se for o caso) 82 responses

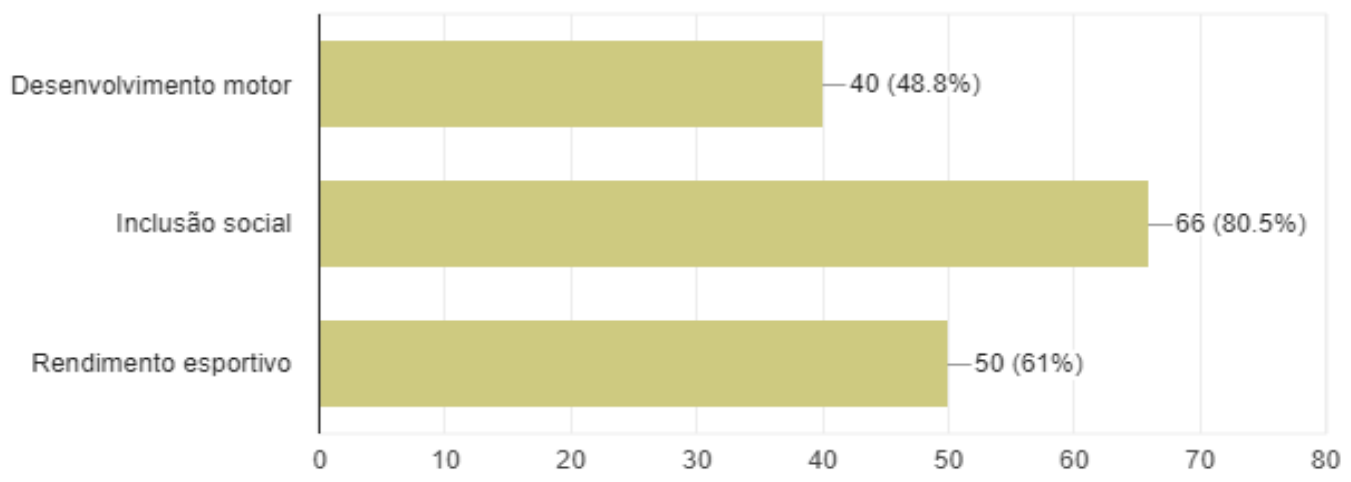

Figura $17-14^{\circ}$ questionamento

Esses últimos dois questionamentos nos mostram uma realidade importante, de que a maioria das OMs que desenvolvem o Profesp busca respeitar as fases de desenvolvimento das crianças e adolescentes, evitando, por exemplo, a busca precoce pelo rendimento esportivo para crianças abaixo de 12 anos, o que só acontece em 17,1\% dos polos dos respondentes e pode ser prejudicial às crianças, como também observaram Gregório e Silva (2014) e Milistetd e Colaboradores (2014). O foco do programa, mesmo na parte esportiva, deve ser o 
desenvolvimento motor e a inclusão social, ensinando às crianças e adolescentes participantes os valores inerentes ao esporte, para contribuir com a formação cidadã desses jovens brasileiros. O surgimento de expoentes esportivos deve ser uma consequência de uma iniciação esportiva bem realizada, com foco no desenvolvimento motor completo das crianças e adolescentes.

São realizados quais testes para mensurar o desenvolvimento das qualidades físicas das crianças ou jovens? (marque mais de uma altemativa, se for o caso)

\section{2 tesponses}

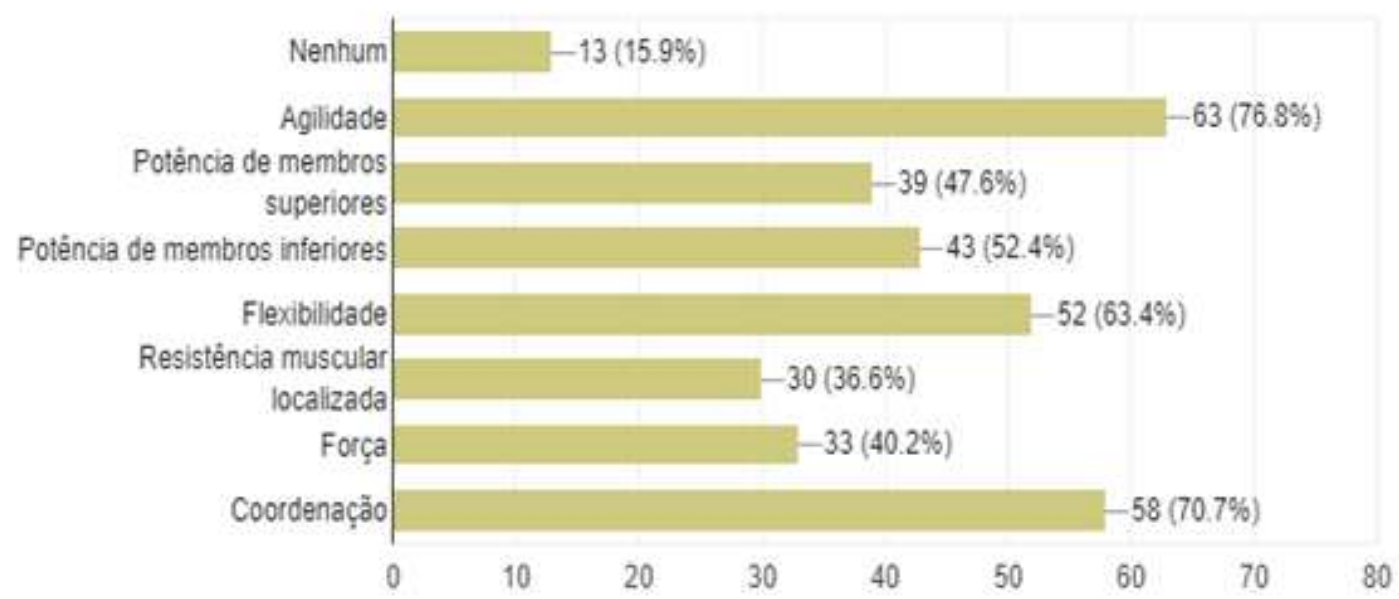

Figura $18-15^{\circ}$ questionamento

Testes de acompanhamento são sempre importantes, principalmente quando falamos de atividade física e esporte, para sabermos se está havendo resultados positivos ou negativos após certo período de realização das atividades. Estas devem contribuir para o aprimoramento motor e a saúde dos participantes.

Apenas 15,9\% dos polos do Profesp respondentes não realizam esse tipo de acompanhamento, mostrando que esta prática comum e importante da educação física não vem sendo negligenciada em grande parte dos polos do programa. 
As crianças ou jovens que se destacam nas modalidades esportivas têm algum tipo de tratamento diferenciado? (marque mais de uma altemativa, se for o caso)

82 responses:

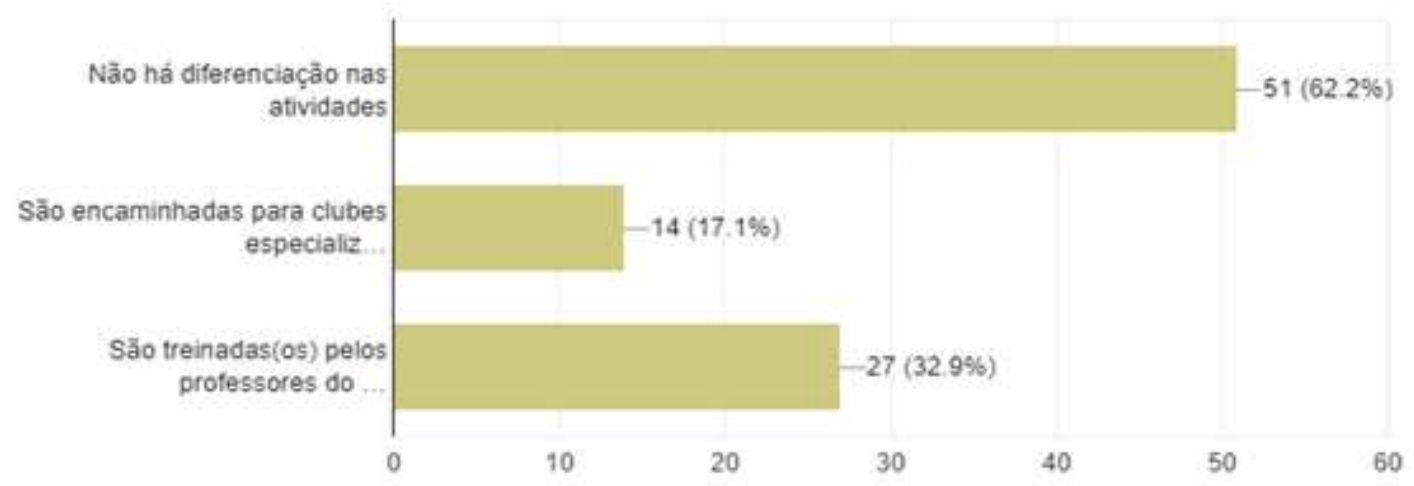

Figura $19-16^{\circ}$ questionamento

O foco do programa deve ser a iniciação esportiva e a inclusão social das crianças e adolescentes. A iniciação esportiva, quando executada corretamente, pode vir a revelar alguns talentos, fazendo com que estes possam vir, futuramente, a ter carreira no mundo esportivo. $\mathrm{O}$ foco do programa, do nosso ponto de vista, nunca pode ser o rendimento esportivo, porém, como um dos focos é a inclusão social, não pode ser negado pelo Profesp, aos participantes com potencial, a oportunidade de desenvolvimento deste, sendo no próprio programa ou em parceria com clubes, como também observaram Vianna e Lovisolo(2011) e Azevedo e Gomes Filho (2011), o que não acontece na maioria dos polos. Caso surja algum expoente esportivo, a esse deve ser dado o direcionamento adequado para aproveitar seu talento e, quem sabe, lhe proporcionar um futuro profissional como atleta de alto rendimento. Porém, o rendimento esportivo deve ser consequência de uma iniciação esportiva bem executada e não o objetivo do programa. 


\section{Aos professores e/ou estagiários são oferecidos cursos/estágios de capacitação?}

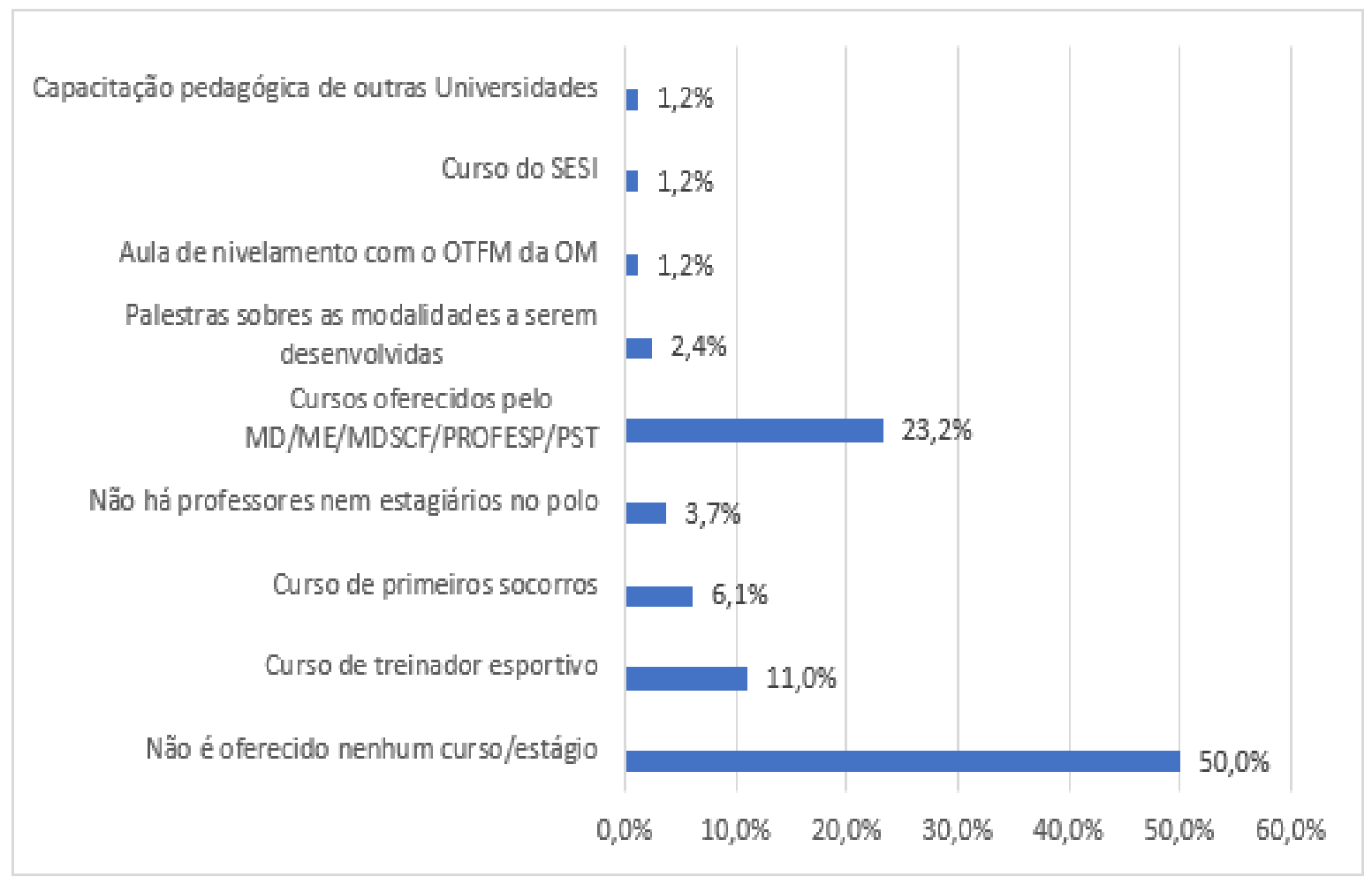

Figura $20-17^{\circ}$ questionamento

A capacitação do pessoal é uma atividade mais do que necessária para o sucesso de qualquer atividade, como também observaram Luguetti e colaboradores (2015). Pelo que foi dito pelos respondentes dos polos do Profesp, em 50\% das OMs não é realizada nenhum tipo de capacitação dos professores orientadores e estagiários, e nos outros $50 \%$ há pouca coisa além da atualização pedagógica anual oferecida pela coordenação geral do programa.

Julgamos extremamente importante que os polos busquem oferecer cursos e estágios aos seus professores e estagiários para o seu aprimoramento técnico profissional, o que trará, como consequência, mais qualidade às atividades desenvolvidas no programa.

A capacitação do quadro de coordenadores, professores e estagiários do programa está diretamente ligada ao sucesso do Profesp. Uma política pública eficiente precisa ter pessoal capacitado nos seus quadros de coordenação, nos mais diversos níveis. A não realização de capacitações em 50\% dos polos respondentes é um dado mais do que preocupante e deve ser um ponto a ser atacado emergencialmente para correção desse índice. 
Quais as formas para obtenção de feedback sobre o rendimento escolar e o comportamento das crianças e jovens participantes após o ingresso no PROFESP? (marque mais de uma alternativa, se for o caso)

82 responses

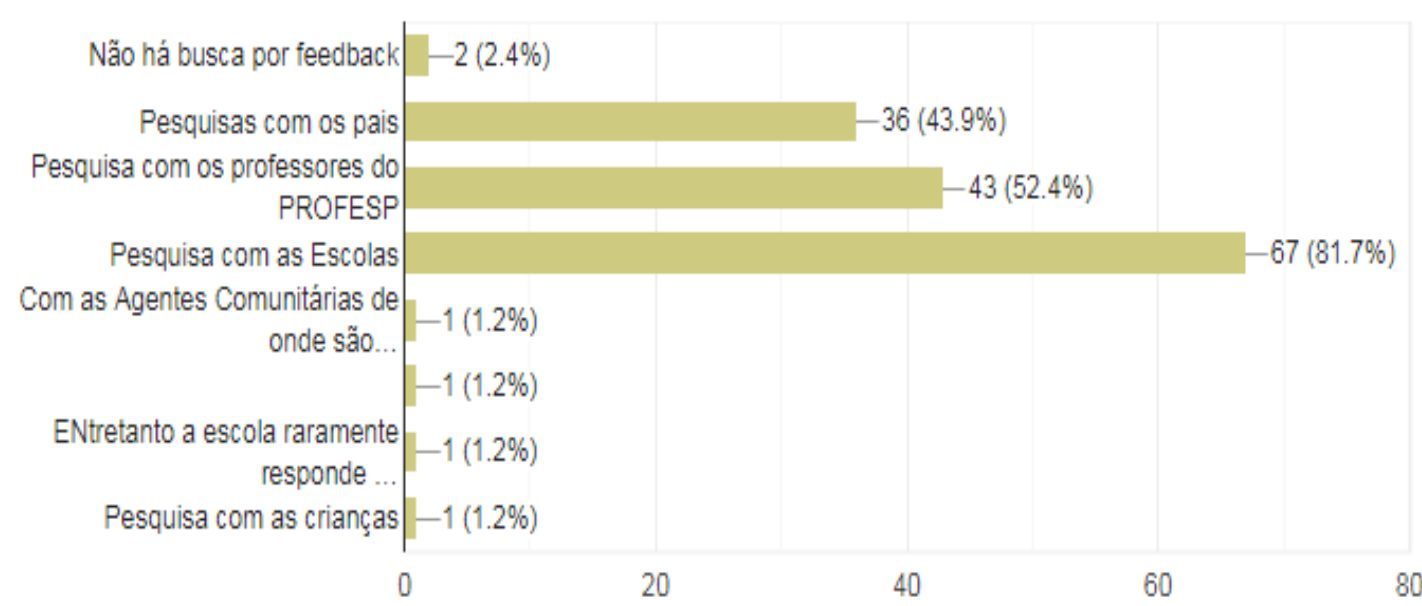

Figura $21-18^{\circ}$ questionamento

A busca por retorno é muito importante para a realização do processo de melhoria contínua das atividades. Neste cerne, com mais de $80 \%$ das OMs buscando retorno sobre os resultados observados nas escolas dos participantes, tem-se boas referências sobre o que manter e o que aprimorar no programa. Contudo, apenas 43,9\% dos pais são consultados, um percentual que julgamos baixo, já que os pais são os que melhor podem dar esse retorno sobre a mudança de comportamento ou não, pra melhor ou pra pior, de seus filhos. Alguns núcleos realizam reuniões mensais com os pais, outros no início e no final de cada período, visando obter retorno e reavaliar o planejamento para as próximas etapas do programa. A opinião das escolas é importante, claro, mas a dos pais pode trazer informação mais fidedigna. Somente $1,2 \%$ dos polos buscam a opinião das crianças e adolescentes. Este percentual também pode ser melhorado, pois os participantes são os principais interessados na atratividade e melhoria do programa, não devendo ser deixados de lado no momento de coleta de opiniões.

Os respondentes das entrevistas comprovaram a falta de padronização no método de desenvolvimento do Profesp ao afirmarem que: "são realizadas pesquisas semestrais" (entrevistado 3); "Realizamos reunião no início e no encerramento das atividades" (entrevistado 2); e "Buscamos realizar reuniões mensais" (entrevistado 1). 
De uma maneira geral, como o senhor(a) avalia o PROFESP no que tange à inclusão social das crianças e jovens participantes?

82 responses
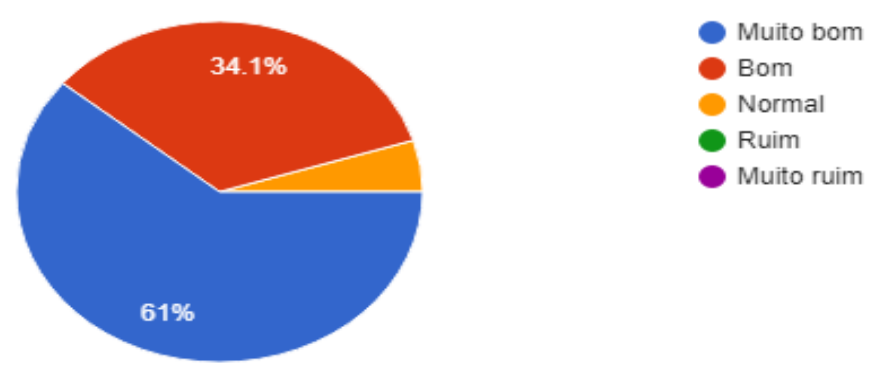

Figura $22-19^{\circ}$ questionamento

De uma maneira geral, como o senhor(a) avalia o PROFESP no que tange ao desenvolvimento motor das crianças e jovens participantes?

82 responses
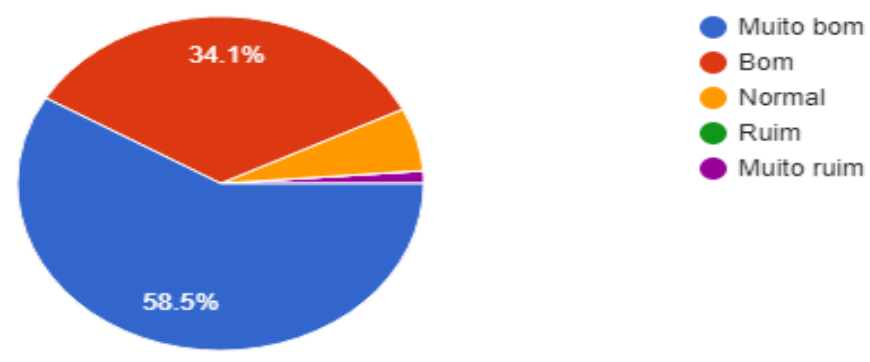

Figura $23-20^{\circ}$ questionamento

De uma maneira geral, como você avalia o PROFESP no que tange ao desenvolvimento esportivo das crianças e jovens participantes?

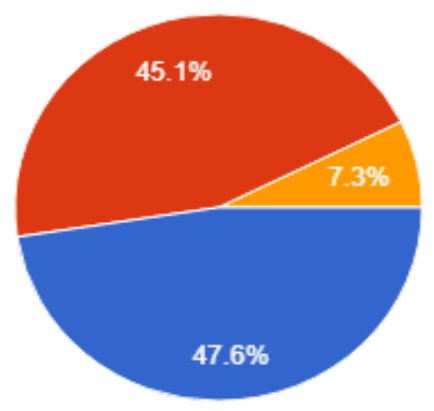

Figura $24-21^{\circ}$ questionamento 


\title{
De uma maneira geral, como o senhor(a) avalia o PROFESP no que tange à formação cidadã das crianças e jovens participantes?

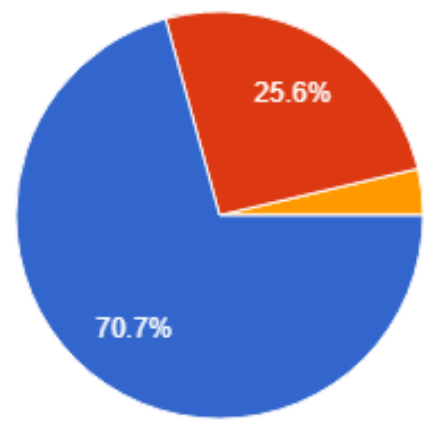

\author{
Muito bom \\ Bom \\ Normal \\ Ruim \\ Muito ruim
}

Figura $25-22^{\circ}$ questionamento

Observando-se a opinião dos respondentes sobre os diversos aspectos que são foco de nosso estudo, como a inclusão social, o desenvolvimento motor, o desenvolvimento esportivo e a formação cidadã, vemos que, em todos os aspectos, entre $92 \%$ e $95 \%$ avaliam como bom e muito bom. Isso mostra que eles estão satisfeitos com o que tem sido desenvolvido e com os resultados alcançados. O que pode ser buscado agora, visando o aprimoramento contínuo, é aumentar o índice de muito bom, buscando a excelência do programa em suas OMs.

Como última pergunta do questionário, foi feita a seguinte indagação: "Quais as sugestões e as oportunidades de melhorias que o senhor(a) identifica no PROFESP, para que o programa contribua cada vez mais para a formação cidadã completa, para a inclusão social e para o desenvolvimento motor e esportivo das crianças e adolescentes participantes?" A partir deste questionamento, muitos comentários foram colocados, sendo os principais:

a) $\mathrm{Na}$ área administrava do programa: contratação de professores e estagiários para o desenvolvimento das atividades, pois o coordenador e o auxiliar não conseguem se envolver diretamente nelas, pois acumulam suas funções nas OMs; envio dos recursos, por parte dos ministérios para os polos, tempestivamente, para aquisição de materiais e contratação de serviços; tentar aumentar os recursos para melhoria das instalações; verificar a viabilidade de aquisição de materiais e uniformes de forma centralizada pela coordenação geral do Profesp, incluindo itens regionais, como luvas, japonas e outros acessórios importantes em regiões de clima frio, dentre outros; oferecer transporte para todos, com contratação de ônibus, tendo em vista que em algumas regiões mais perigosas, as FFAA não podem entrar com segurança; aumentar o número de OMs participantes do Profesp para beneficiar 
mais crianças. Para isso o MD teria de fazer uma campanha de divulgação dos benefícios que o programa pode trazer para os quartéis, visando tornar a implantação atrativa aos comandantes; buscar maior exposição do programa na mídia para facilitar a busca por parceiros nas diversas áreas que possam vir a beneficiar as crianças e adolescentes do Profesp; e buscar que não haja interrupção nas atividades dos polos, que sejam ações continuadas, respeitando somente as férias da escola dos participantes.

b) Na área educacional, social e de capacitação profissional do programa: estímulo à maior interação com as prefeituras e suas secretarias visando maior suporte pedagógico aos participantes; enfatizar a formação cidadã, sem prejuízo dos demais aspectos, pois as crianças serão difusoras das boas atitudes e valores aprendidos no programa; buscar oferecer cursos e palestras sobre definição profissional e formação familiar, além de buscar parcerias com clubes, escolas e cursos para dar oportunidades aos jovens após a idade-limite de permanência no programa; se possível, dar algum tipo de assistência e suporte às famílias; oferecer cursos e estágios aos professores e estagiários do programa, assim como cursos e estágios profissionalizantes para as turmas mais próximas de "estourar" a idade de permanência; realizar competições esportivas regionais e nacionais entre os polos, visando maior integração e congraçamento entre estes; buscar formas atrativas para se conseguir mais estagiários, como validação de carga horária de estágios obrigatórios das universidades, remuneração, transporte, alimentação, dentre outras possibilidades; e criar, por parte do MD, cartilhas sobre cidadania, civismo, patriotismo, valores morais, saúde etc, para distribuição às OMs para padronização do conteúdo ministrado.

Já nas entrevistas, além dos pontos já citados na apresentação e discussão dos resultados, algumas respostas que podemos destacar foram que:

a) "quem seleciona os alunos é a prefeitura" (entrevistado 2); "a seleção dos participantes é feita pelos agentes comunitários" (entrevistado 1); e "as próprias escolas escolhem quais alunos vão participar". Mais uma vez fica comprovada a falta de padronização nos processos do Profesp, fazendo-se necessária uma padronização que sirva de norte para o desenvolvimento do programa em toda e qualquer OM do Brasil;

b) "os recursos enviados pelos ministérios não são suficientes para adaptação das áreas esportivas" (entrevistado 1); "os uniformes são adquiridos centralizadamente, porém a verba para aquisição de material esportivo e para manutenção das quadras é muito pequeno" (entrevistado 2); e "o recurso que recebemos para manutenção das 
instalações esportivas não cobre todas as despesas, sendo necessário que o quartel use verba que seria para outras atividades" (entrevistado 3). A opinião dos entrevistados mostra que é necessário buscar junto aos ministérios apoiadores do Profesp, principalmente o Ministério do Esporte, recursos compatíveis com as necessidades de adaptação, modernização e/ou reestruturação das áreas esportivas das OMs.

\section{Conclusão}

Como alternativa à situação de falta de prática de atividade física e esporte nas escolas e de espaço para a prática nas cidades, muitos programas/projetos sociais esportivos (PSE) vêm sendo desenvolvidos no meio público ou privado.

Políticas públicas como o PST e o Profesp ainda serão necessárias em muitas oportunidades, assim como o PSE da iniciativa privada, pois durante um tempo considerável ainda haverá escolas sem espaço para que seja criada estrutura esportiva adequada à prática de atividade física e de esportes. Contudo, vemos que esses programas devem ser uma forma de apoio onde não há alternativa para a garantia do direito das crianças e dos adolescentes, não a solução final para a falta de estrutura esportiva adequada das escolas brasileiras.

Os PSEs contribuem consideravelmente para a melhoria da qualidade de vida das crianças e adolescentes por meio do ensino de valores diretamente ligados à prática esportiva como o jogo limpo, o trabalho em equipe, o respeito às regras, a coragem, a dedicação e a superação, entre outros.

Alguns programas/projetos vão além da parte física e esportiva, oferecendo atendimento médico e odontológico, acompanhamento psicológico e terapêutico, aulas de civismo, reforço escolar, ensino profissionalizante e outras atividades que possam vir a beneficiar os participantes que estão em processo de formação de sua cidadania.

O Profesp, segundo os respondentes do questionário e os entrevistados, segue a mesma linha dos programas/projetos mais completos, podendo vir a oferecer vários tipos de atividades. Em muitos polos, isto é impossibilitado, pois as OMs das FFAA, em particular da Força Aérea e do Exército, têm tido dificuldades administrativas na contratação direta de profissionais das áreas de interesse para montagem de equipe multidisciplinar, ficando na dependência de conseguir parcerias que disponibilizem esses profissionais e, assim, desenvolver as mais variadas atividades com os participantes do programa.

Outro ponto em que o Profesp se assemelha aos demais PSEs é no tocante às suas barreiras e facilitadores, já que oferece as mesmas oportunidades dos demais e encontra as mesmas dificuldades, como a falta ou desistência de crianças por necessidades domésticas, a dificuldade de locomoção das crianças para os núcleos onde não é ofertado transporte, a falta de incentivo de alguns responsáveis, entre outras. Isso acaba contribuindo para a ausência ou até 
mesmo a desistência em prosseguir no programa por algumas crianças e adolescentes.

Também observamos que os PSEs e o Profesp têm que ter cuidado para não incorrer em um erro comum, o de realizar a especialização precoce das crianças, deixando de dar ênfase à formação cidadã dos participantes e buscando o rendimento esportivo fora do momento ideal.

Como sabemos, a correta iniciação esportiva e a prática contínua podem vir a desenvolver o talento de algumas crianças e adolescentes, o que não lhes pode ser negado, porém isso nunca pode ser o foco do PSE ou do Profesp, e sim uma consequência de um trabalho bem realizado, sem que as etapas sejam desrespeitadas. $\mathrm{O}$ foco principal deve ser a inclusão social das crianças e adolescentes em situação de vulnerabilidade social por meio da prática de atividade física e esporte.

Inicialmente imaginávamos que o Programa Forças no Esporte, devido à capilaridade nacional das organizações militares das Forças Armadas, teria um potencial altíssimo de contribuição no que tange à realização de prática de atividade física e esporte por crianças e adolescentes em situação de vulnerabilidade social e que estudassem em escolas sem infraestrutura esportiva disponível. Assim se tornaria fator determinante para a inclusão social e o desenvolvimento esportivo no Brasil.

Porém, analisando os números absolutos, em que vimos que o Profesp atende atualmente cerca de 23,7 mil crianças de 6 a 18 anos, num país onde, de 6 a 14 anos, temos um universo de mais de 26,2 milhões, constatamos que essa contribuição ainda é muito pequena, quase insignificante. Só não consideramos irrisória a contribuição porque a garantia do direito à prática de atividade física e ao esporte a cada criança e adolescente já é um grande avanço. E mesmo que não alcance os milhões que precisam ser alcançados, o Profesp garante o direito de quase 24 mil crianças. Isso, sem mencionarmos que o programa é uma vertente de outra política pública nacional, o Programa Segundo Tempo.

Em 2018 tínhamos, em média, 150 participantes por núcleo do programa. Mesmo se todas as 850 OMs das FFAA possuíssem núcleos, mantendo essa média, seriam atendidas cerca de 127,5 mil crianças e adolescentes, ou seja, ainda uma contribuição muito pequena.

Mais uma vez, há que ser considerado que já é bastante válido qualquer jovem ter seu direito à prática de atividade física e esporte garantido. Porém, mesmo que as FFAA quisessem atender a todas as crianças e adolescentes vulneráveis, isso não seria possível. Por mais importante que seja o Profesp na vida dos seus milhares de participantes, ele não tem como alcançar parcela significativa do público-alvo, pois o número de OMs é limitado e a realização desse programa é uma missão secundária das Forças Armadas, fazendo com que muitos comandantes de organizações militares optem por não realizá-lo e priorizem a atividade-fim de seus quartéis, ou seja, a atividade inerentemente militar.

Para que haja uma solução mais efetiva e que atenda aos milhões de jovens do Brasil, entendemos que o ideal seria a realização de políticas públicas e outros incentivos para a 
disponibilização de infraestrutura adequada à prática de atividade física e esporte nas próprias escolas.

Com isso, concluímos que o Profesp é fator de inclusão social e desenvolvimento esportivo no Brasil, porém não é determinante, tendo em vista o número que crianças e adolescentes participantes, entre 6 e 18 anos em 2018 (23,7 mil), face ao contingente total de crianças e adolescentes entre 6 e 14 anos (mais de 26,2 milhões).

Porém não podemos desconsiderar a importância do programa para os milhares de cidadãos em formação que são atendidos, os quais têm garantido o seu direito à prática de atividade física e esporte, além de outros benefícios que o Profesp oferece, como os mencionados pelos respondentes aos questionários ou entrevistas, como, por exemplo, reforço escolar, cuidados com saúde física e mental, inclusão social, civismo, dentre outros que foram apresentados pelos coordenadores dos núcleos do programa.

Também observamos, por meio das opiniões, que o programa apresenta diversas oportunidades de melhoria do atendimento a seus participantes, como, principalmente, maior aporte de recursos e de forma mais tempestiva (para aquisição de materiais e manutenção das instalações), e soluções administrativas para possibilitar a contratação dos profissionais de diversas áreas, a fim de formar equipe multidisciplinar e oferecer a maior quantidade de atividades possíveis, importantes para contribuir com a formação cidadã das crianças e adolescentes participantes.

Como oportunidade de novos estudos, achamos válida a busca pelas observações e opiniões de professores, estagiários, parceiros, escolas, pais/responsáveis e das crianças e adolescentes participantes do Profesp que não foram alvo de observação deste estudo, além da pesquisa de possibilidades administrativas para que a administração pública consiga contratar os profissionais necessários para a realização do programa.

\section{Referências}

ALVES, H. C.; CHAVES, A. D.; GONTIJO, D. T. "Uma Andorinha Só Não Faz Verão": a Integração Do Educador Físico Na Rede De Suporte Social De Crianças E Adolescentes Em Situação De Vulnerabilidade - Discussões a Partir De Um Curso De Educação Continuada. Pensar a Prática, v. 15, n. 2, p. 331-347, 2012.

ANDRÉ LUIZ PEREIRA SPINIELI. Mas afinal o que é inclusão social? Disponível em: $<$ http://www.justificando.com/2018/08/13/mas-afinal-o-que-e-inclusao-social/>. Acesso em: 9 nov. 2018.

ARANHA, J. G. Impacto de um programa público de iniciação esportiva para crianças: gastos, antropometria, rendimento escolar e qualidade de vida. São Paulo: USP, 2014.

AZEVEDO, M. A. O. DE; GOMES FILHO, A. Competitividade E Inclusão Social Por Meio Do Esporte. Rev. Bras. Ciênc. Esporte, Florianópolis, v. 33, n. 3, p. 589-603, 2011.

BRASIL. Constituição da República Federativa do Brasil. Disponível em: $<$ http://www.planalto.gov.br/ccivil_03/constituicao/constituicaocompilado.htm>. Acesso em: 30 maio. 2019. 
BRASIL. Lei $n^{0}$ 8069, de 13 de julho de 1990 - Estatuto da Criança e do Adolescente. Disponível em: <http://www.planalto.gov.br/ccivil_03/leis/18069.htm>. Acesso em: 29 maio. 2019.

BRASIL. Portaria Normativa Interministerial No 2.203/MD/ME, 2013.

BRASIL. Programa Forças no Esporte. Disponível em: $<$ http://www.defesa.gov.br/programas-sociais/programa-forcas-no-esporte $>$. Acesso em: 30 jan. 2018.

CORTES NETO, E. D.; DANTAS, M. M. C.; MAIA, E. M. C. Benefícios dos projetos sociais esportivos em crianças e adolescentes. Saúde e Transformação Social, v. 6, p. 109-117, 2015.

COSTA, R. DE S. O. DA. Considerações sobre um programa esportivo de iniciativa do governo federal brasileiro. nov. 2006.

DE CASTRO, S. B. E.; SOUZA, D. L. Significados de um projeto social esportivo: Um estudo a partir das perspectivas de profissionais, pais, crianças e adolescentes. Movimento, v. 17, n. 4, p. 145-163, 2011.

EB. Quartéis por Estado - Exército Brasileiro. Disponível em: $<$ http://www.eb.mil.br/quarteis-por-estado1>. Acesso em: 3 nov. 2018.

EIRAS, S. B. et al. Objetivos da oferta e da procura de projetos sócio- esportivo. Licere, v. 13, n. 3, p. 1-24, 2010.

ENES, C. C.; SLATER, B. Obesidade na adolescência e seus principais fatores determinantes. Revista Brasileira de Epidemiologia, v. 13, n. 1, p. 163-171, 2010.

FAB. Força Aérea Brasileira - Asas que protegem o país. Disponível em: $<$ http://www.fab.mil.br/organizacoes $>$. Acesso em: 3 nov. 2018.

FORTUNA, D. MEC divulga dados do Censo Escolar da educação básica. Correio Braziliense, 2018.

FRANKENTHAL, R. Entenda o que é Escala Likert e como aplicá-la - MindMiners. Disponível em: <https://mindminers.com/pesquisas/entenda-o-que-e-escala-likert>. Acesso em: 4 mar. 2018.

GAZETAONLINE. Estudo da ONU destaca a falta de atividade física nas escolas públicas. Disponível em: <https://www.gazetaonline.com.br/esportes/mais_esportes/2017/11/estudo-daonu-destaca-a-falta-de-atividade-fisica-nas-escolas-publicas-1014105918.html $>$. Acesso em: 4 nov. 2018.

GREGÓRIO, K. M.; SILVA, T. Iniciação esportiva X especialização esportiva precoce: quando iniciar estas práticas? Horizontes- Revista de Educação, v. 2, n. 3, p. 49-65, 2014.

IBGE. Educação 2017 - PNAD. Disponível em: <https://www.ibge.gov.br/estatisticasnovoportal/sociais/>. Acesso em: 3 nov. 2018.

JANUZZI, A. M.; GUEDES, G. B. Programa Forças no Esporte na Base Aérea de Natal: a integração entre a educação escolar e a prática desportiva na socialização de jovens em situação de risco. Natal: UFRN, 2015.

LUGUETTI, C. N. et al. O planejamento das práticas esportivas escolares no ensino fundamental na cidade de Santos. Revista Brasileira de Ciencias do Esporte, v. 37, n. 4, p. 314-322, 2015.

MARIA, A.; MARTINS, M.; RENNÓ, T. Esportes no Brasil: situação atual e propostas para desenvolvimento. BNDES, p. 154-168, 1997.

MARINHA. Sites das Organizações | Marinha do Brasil. Disponível em: <https://www.marinha.mil.br/content/sites-das-organizacoes>. Acesso em: 3 nov. 2018.

MCLENNAN, N. The Power of Sport Values O poder dos valores do esporte. Brasília: UNESCO, 2016.

MENDES, R. R.; DE MATOS, J. A. B.; DE PINHO, A. C. Propostas Metodológicas da Iniciação Esportiva Escolar. n. 1993, p. 1-13, 2010. 
MENEZES, R. P.; MARQUES, R. F. R.; NUNOMURA, M. Especialização esportiva precoce e o ensino dos jogos coletivos de invasão. Movimento, v. 20, n. 1, p. 351-373, 2014.

MILISTETD, M. et al. Análise da organização competitiva de crianças e jovens: adaptações estruturais e funcionais. Revista Brasileira de Ciências do Esporte, v. 36, n. 3, p. 671-678, 2014.

ONU-BR. Esporte para o desenvolvimento e a paz, 2016.

OSBORNE, R.; DOS SANTOS, R. F. Implicações de projetos educativos atuais para a educação física e a escola pública. Corpus et Scientia, v. 8, n. 2, p. 21-35, 2015.

PALMA, M. S.; DE CAMARGO, V. A.; PONTES, M. F. P. Efeitos da atividade física sistemática sobre o desempenho motor de crianças pré-escolares. Revista da Educacao Fisica, v. 23, n. 3, p. 421-429, 2013.

PEREIRA, I. I. L.; DIAS, M. A. Narrativas visuais: sentido e motivação do adolescente sobre o programa segundo tempo - Forças no Esporte. 2016.

REIS, N. S. et al. O Esporte Educacional Como Tema Da Produção De Conhecimento No Periodismo Científico Brasileiro: Uma Revisão Sistemática. Pensar a Prática, v. 18, n. 3, p. 709-724, 2015.

RIBAS, P. R. CITIUS, ALTIUS, FORTIUS. A ARTE DE TREINAR PARA VENCER: O ESPORTE IMITA A GUERRA. REVISTA DE EDUCAÇÃO FÍSICA / JOURNAL OF PHYSICAL EDUCATION, v. 138, p. 55-62, 2007.

SANCHES FILHO, R. R.; BARRETO, M. O. PERSPECTIVAS DA FORMAÇÃO INTEGRAL DO PROFESSOR DE EDUCAÇÃO FÍSICA E SUA ATUAÇÃO NO PROGRAMA SEGUNDO TEMPO - FORÇAS NO ESPORTE. Bahia: 2010.

SANCHES, S. M.; RUBIO, K. A prática esportiva como ferramenta educacional: trabalhando valores e a resiliência. Educação e Pesquisa, v. 37, n. 4, p. 825-841, 2011.

SANTOS, A. M.; NETO, F. R.; PIMENTA, R. A. Avaliação das habilidades motoras de crianças participantes de projetos sociais/esportivos. Motricidade, v. 9, n. 2, p. 50-60, 2013.

SECCO, M. B. G. Mauro B. G. Secco - Cel (MSc). Rio de Janeiro: 2017

SIGNIFICADOS. Significado de Inclusão social - O que é, Conceito e Definição. Disponível em: <https://www.significados.com.br/inclusao-social/>. Acesso em: 9 nov. 2018.

SILVA PERFEITO, R.; MAGAlHÃES DE SOUZA, W. M.; DE SÁ ALVES, D. G. Treinamento de força muscular para crianças e adolescentes: Benefícios ou malefícios? Adolescencia e Saude, v. 10, n. 2, p. 54-62, 2013.

SIMÕES, P. DE T. et al. EDUCAÇÃO FÍSICA , ESPORTE E DESENVOLVIMENTO SUSTENTÁVEL NO PROGRAMA ESCOLA ABERTA. Revista Intercontinental de Gestão Desportiva, v. 1, n. 1, p. 33-43, 2011.

SOUZA, D. L. DE S. et al. Determinantes para a implementação de um projeto social. Motriz, v. 16, n. 3, p. 689-700, 2010.

SOUZA, C. E. DE. ESTADO COSMOPOLITA, ORGANISMOS INTERNACIONAIS E A TERCEIRA VIA: o esporte enquanto Política Social. Motrivivência, v. 26, n. 4, p. 41-54, 2014.

SOUZA, D. L. DE; CASTRO, S. B. E. DE; MEZZADRI, F. M. Facilitadores e barreiras para a implementação e participação em projetos sociais que envolvem atividades esportivas: os casos dos projetos Vila na Escola e Esporte Ativo. Revista Brasileira de Educação Física e Esporte, v. 26, n. 3, p. 419-430, 2012.

SOUZA, D. L. DE; CASTRO, S. B. E. DE; VIALICH, A. L. Barreiras e facilitadores para a participação de crianças e adolescentes em um projeto socioesportivo. Revista Brasileira de Ciências do Esporte, v. 34, n. 3, p. 761-774, 2012.

STIGGER, M. P.; THOMASSIM, L. E. Entre O "Serve" E O "Significa": Uma Análise Sobre Expectativas Atribuídas Ao Esporte Em Projetos Sociais. Licere, v. 16, n. 2, p. 1-33, 2013. 
THOMASSIM, L. E. C.; STIGGER, M. P. O "público-alvo" nos bastidores da política: um estudo sobre o cotidiano de crianças e adolescentes que participam de projetos sociais esportivos. Porta Alegre: 2010.

THOMÉ, C. Estrutura esportiva em escolas é deficitária, mostra pesquisa do IBGE. ESTADÃO, 2017.

UNESCO. A UNESCO e o esporte, 2013.

VIANNA, J. A. Projetos de inclusão social por meio do esporte: localização e adesão. EFDeportes. com, Revista Digital, v. Año 18, n. 184, p. 1-8, 2013.

VIANNA, J. A.; LOVISOLO, H. R. A inclusão social através do esporte: a percepção dos educadores. Revista Brasileira de Educação Física e Esporte (Impresso), v. 25, n. 2, p. 285296, 2011.

VILLAS, R.; LIMA, B. Impacto da atividade física e esportes sobre o crescimento e puberdade de crianças e adolescentes. Revista Paulista de Pediatria, v. 26, n. 4, p. 383-391, 2008.

Artigo recebido em: 26/06/2019

Artigo aceito para publicação em: 09/09/2019 